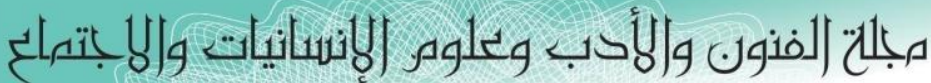

Journal of Arts, Literature, Humanities and Social Sciences

ISSN online: 2414 - 3383

ISSN print: $\mathbf{2 6 1 6 - 3 8 1 0}$

دِيسور 2019

Volume (47)
(47) العدد

December 2019
CALHSS www.jalhss.com

\title{
تاريخ الشرق في مسرحيات شكسبيز، نقد وإعادة بناء
}

م. د. محمد حموز لقته الغانمي

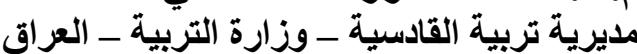

MaLghanmy612@gmail.com

|لماخص

نالَّ تاريخ الثرق اهتماماً كبيراً من لدن مؤرخي الغرب نتيجة لما يتمتع به من مقومات حضارية ونقافية وفكرية، لذا جاء اهتمام المستشرقين بدراسة جوانبه التاريخية والادبية على نطاق واسع، ومع أن هناك من يعتقد بأنَّ

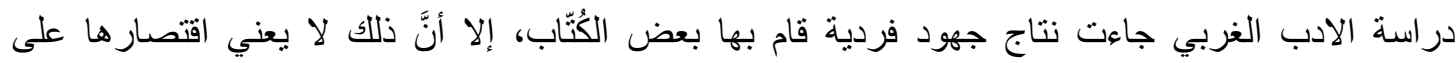
المحاو لات الذاتية فقط بل برزت العديد من الاهتمامات الحكومية لدول الغرب من خلال فتح العديد من مر اكز الاختصاص التي عملت على در اسة الثرق بمختلف المجالات. و عندما كان الادب مر آة عاكسة لقضايا المجتمعات، نشط الادب الغربي بدراسة الجوانب الاجتماعية التي

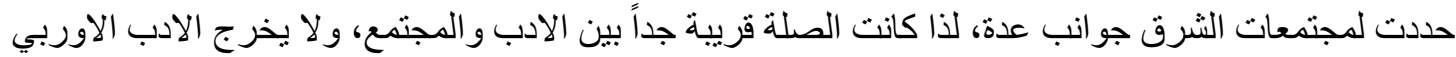
عن تلك العلاقة الوظيفية مع المجتمع بجوانبه المختلفة، وعلى هذا الاساس جاء اهتمام شكسبير بالأدب الاجتماعي كبيراً جداً إلى درجة عدَّ نتاجه الادبي تصويرًا للمجتمع الاوربي بجميع قضاياه ومختلف طبقاته، لقد

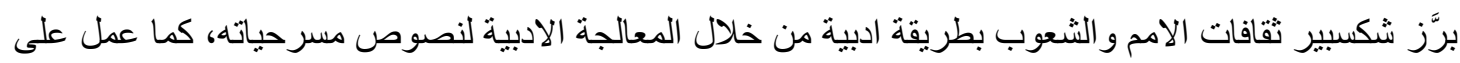
توضيح رؤى و افكار كتّابها، وقدمها بطريقة بسيطة سهلة الهضم للمجتمع، لذلك شكلت مسرحياته نافذة واسعة لتصوير المجتمع بسائر طبقاته واجناسه من خلال شخوص مسرحياته وحوار اتهم، ونتيجة لذلك الاهتمام جاءت در استنا لموضوع (تاريخ الثرق في مسرحيات شكسبير، نقد وإعادة بناء) بغية تقصى تلك الجو انب لاسيما التي ارتبطت بصورة الجوانب الاخرى التي جسدها في مسرحياته لاسيما صورة المسلم. 


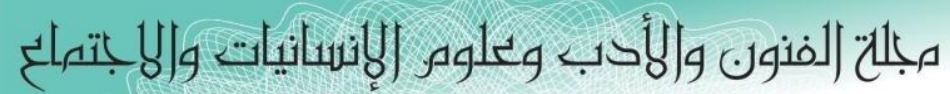

Journal of Arts, Literature, Humanities and Social Sciences

ISSN online: 2414 - 33832019 ديسمبر

ISSN print: 2616 - 3810

Volume (47)

العدد (47)

December 2019

\title{
History of the East in Shakespeare's Plays, Critique and Reconstruction
}

\author{
Dr. Muhammed H. L. Al-Ghanmi
}

\begin{abstract}
The history of the East has received great attention from the historians of the West due to the elements of literature and high civilization, so the Orientalists came to study its historical and literary aspects on a large scale. Although there are those who believe that the study of Western literature was the result of individual efforts by some writers. However, this does not mean that it is limited to self-attempts only, but many of the governmental concerns of the West have emerged through the opening of

several centers of specialization that have worked to study the East in various fields. When literature was a mirror reflects the issues of societies, Western literature was active in studying the social aspects that defined the societies of the East in many ways, so the connection was very close between literature and society. The European literature does not exclude this functional relationship with society in its various aspects. On this basis, Shakespeare's attention to social literature is very great to the extent that his literary output is a depiction of European society in all its issues and its different layers. Shakespeare has developed the cultures of nations and peoples in a literary way through the literary treatment of the texts of his plays, and has worked to clarify the views and ideas of it's authors. And presented in a simple way easy to digest through the society.
\end{abstract}




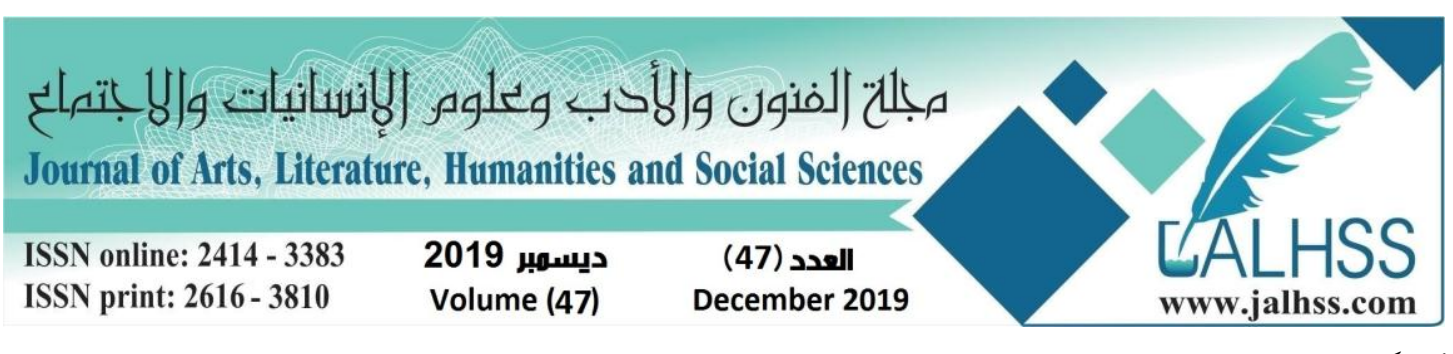

أولاً: صورة الثرق في مسرحيات شكسبير

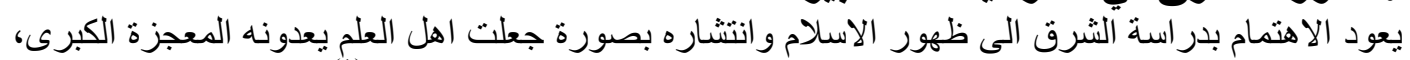

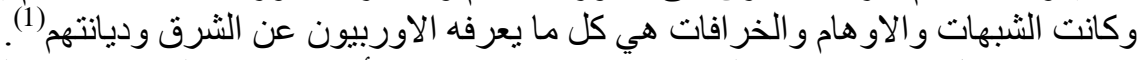

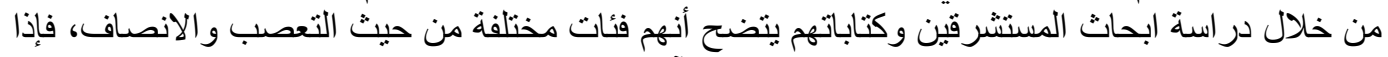

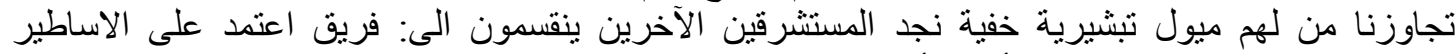

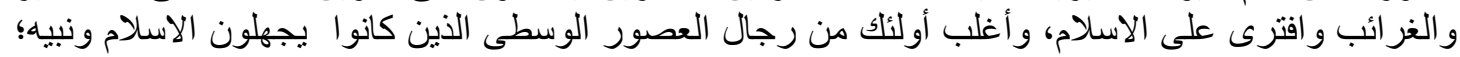

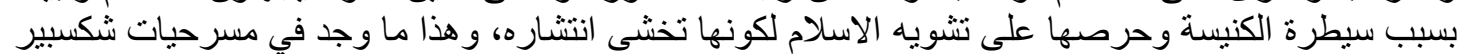

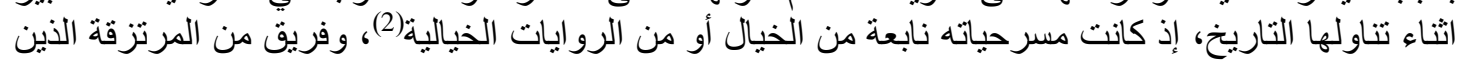

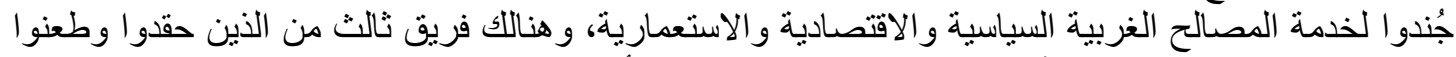

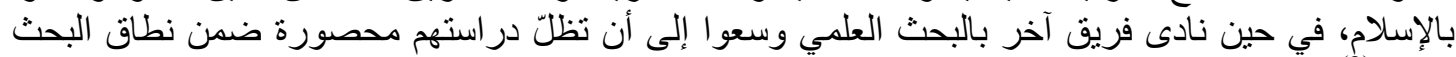

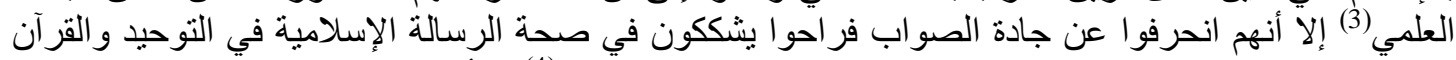

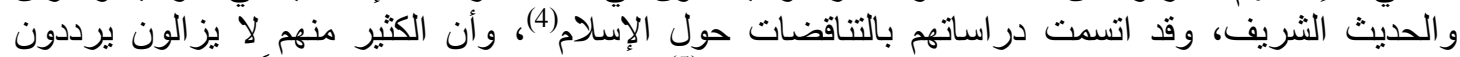

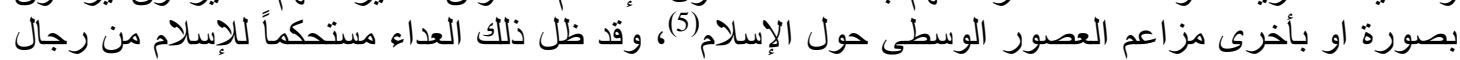

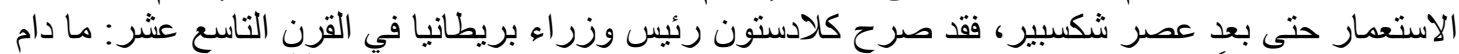

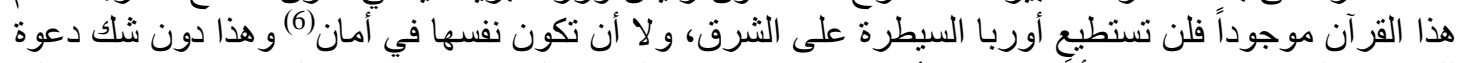

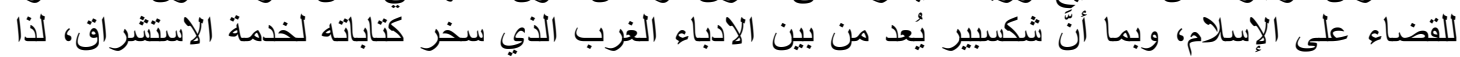

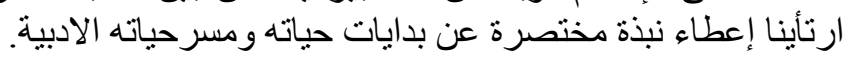
نبذة عن حياة وليم شكسبير.

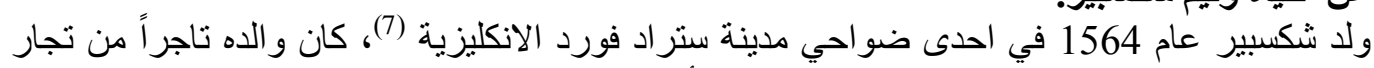

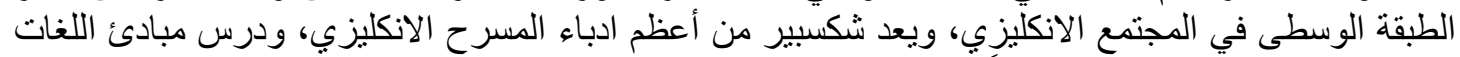

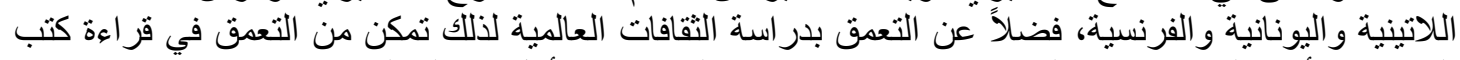

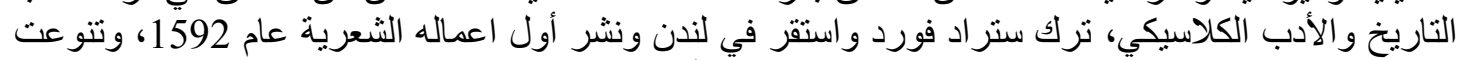

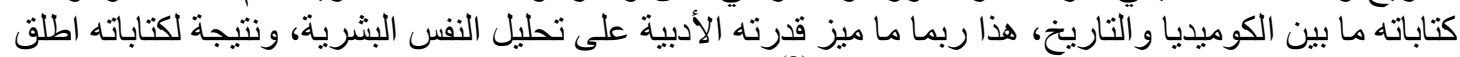

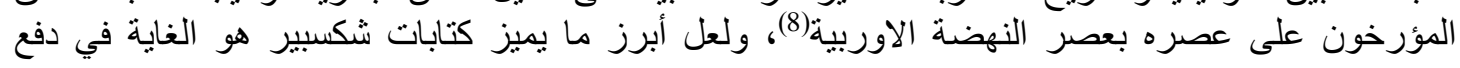

(1) عبد القهار داود عبد الله العاني، الاستشراق و الدراسات الاسلامية، دار الفرقان للنشر و التوزيع، عمان،2000، ، ص7. ير اجع للمزيد:

Richard F. Burton, The book of the Thousand nights and A night, Vol. 10, Oxford, 1885.

(2) Jose Manuel Gonzalez, Shakespeare's Use of History in Escalas Criticism, Universitat d'alacant, 1998, P.295.

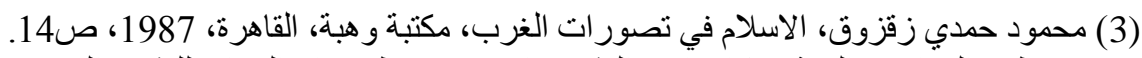
(4) مصطفى السبّاعي، السنة ومكانتها في التشريع الاسلامي، ط2، دارئ دار الوراق للنشر والتوزيع ـ المكتب الاسلامي، د. م،

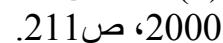

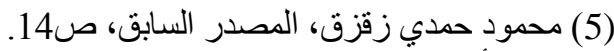

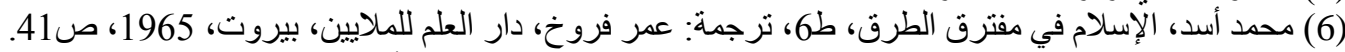

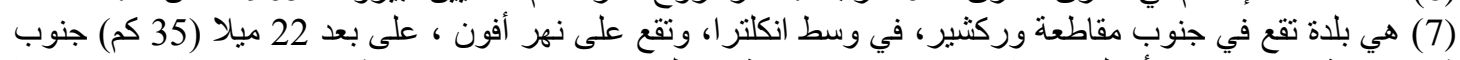

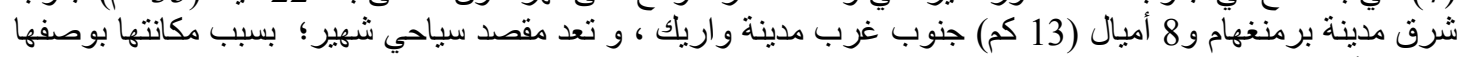

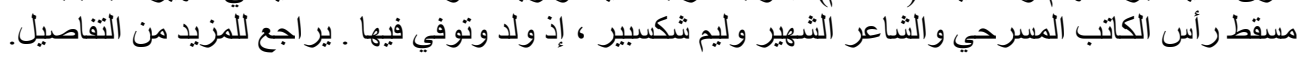
Stratford-on-Avon District Local Plan Review 1996-2011, Revised Deposit Draft, January. 2003 , P. 7; MLA Style: "Stratford-on-Avon.", Encyclopedia Britannica, 2010.

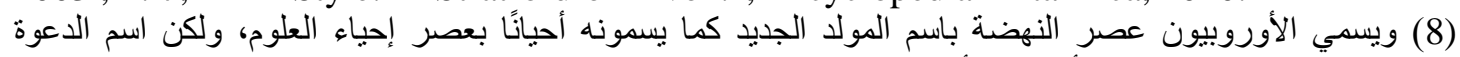

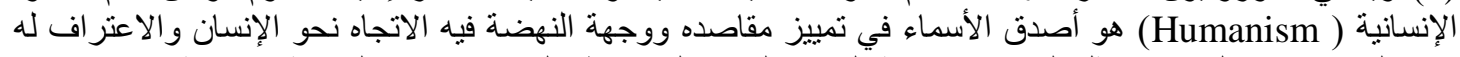

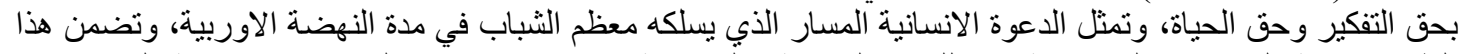

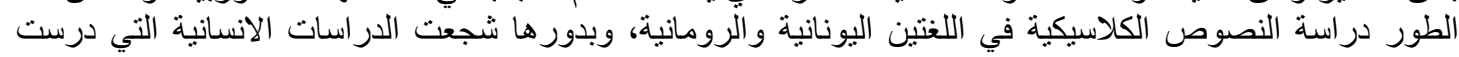

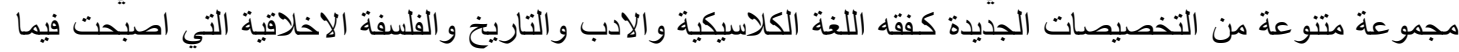


مبلحت (لفنون والأدب وعلوه الإنسانيات والبانتهاع Journal of Arts, Literature, Humanities and Social Sciences

ISSN online: 2414 - 3383

ISSN print: 2616 - 3810

\section{ديسمبر 2019 \\ Volume (47)}

(47) العدد)

December 2019

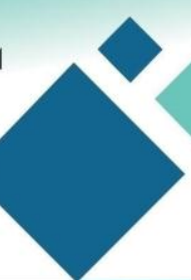

LALHSS www.jalhss.com

الانسان للتفكير، و الاعتراف بحقه للعيش بحياة كريمة بعيدة عن الاضطهاد(1)، كما انه اعتمد كتابات مؤرخي

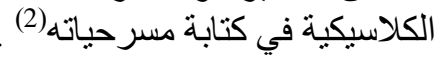

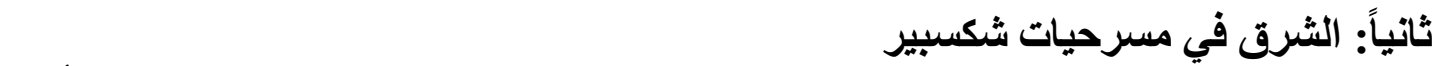

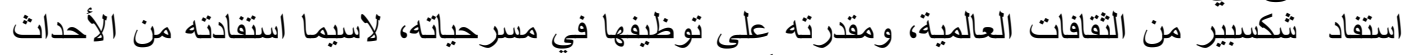

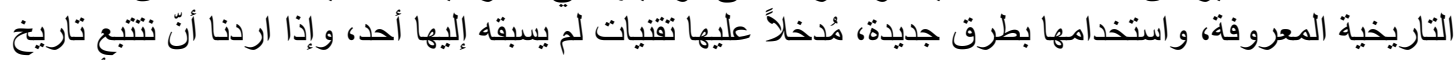

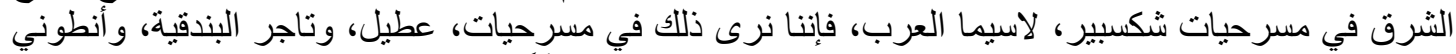

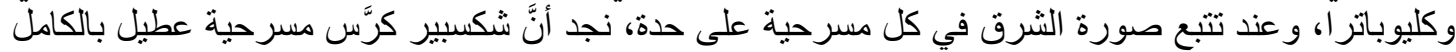

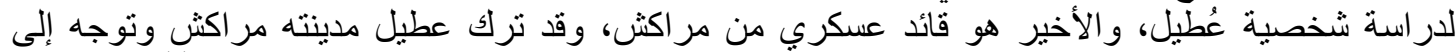

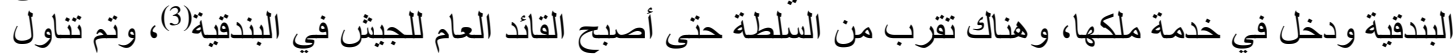

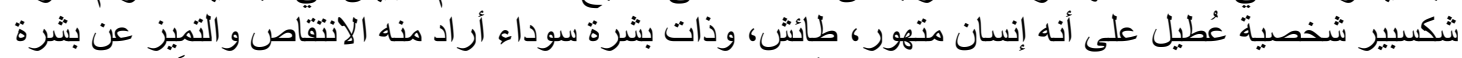

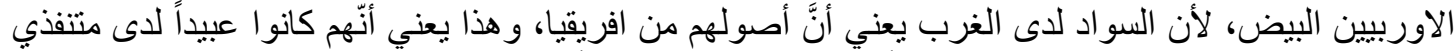

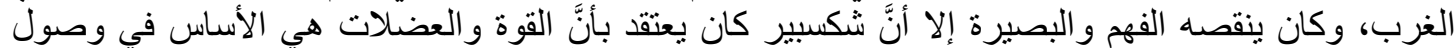

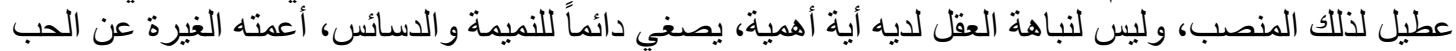

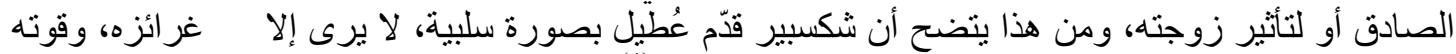

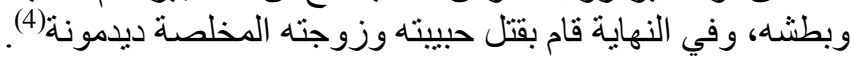

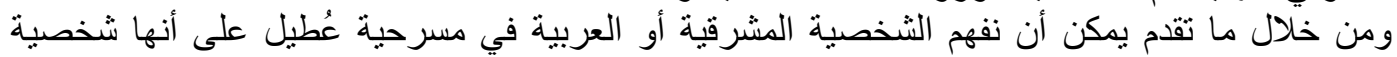

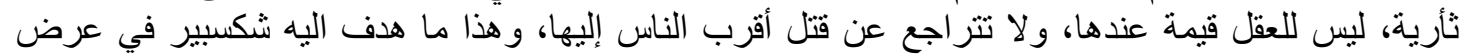

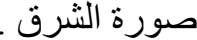
كما مثلت مسرحبة عُطيل نموذجاً للحياة الانسانية، لكون الحب و والغيرة و العاطفة من سمات المجتمع، فعطيل

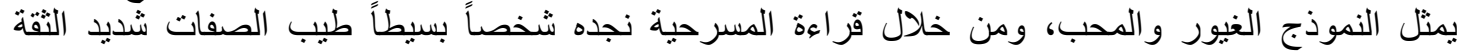

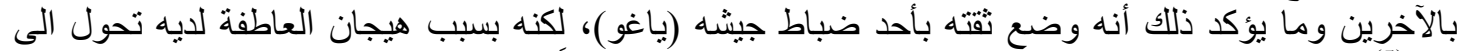

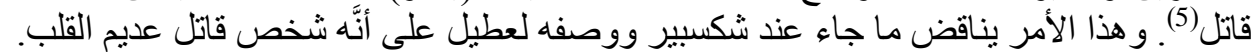

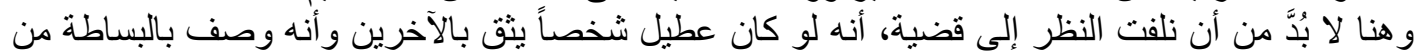

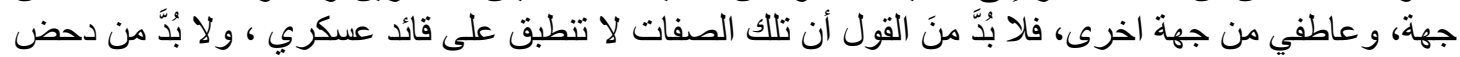

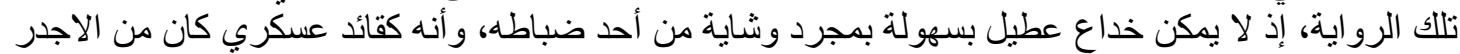

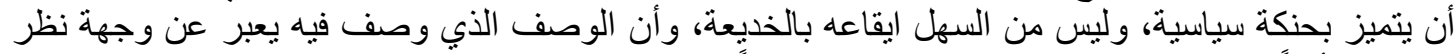

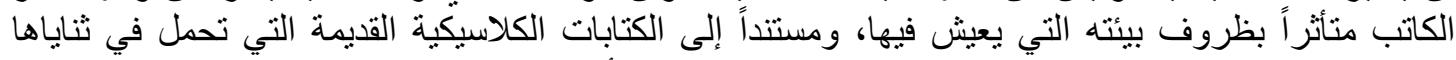

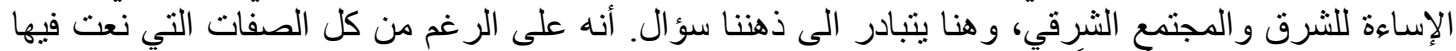

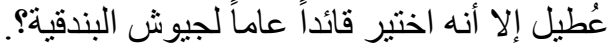

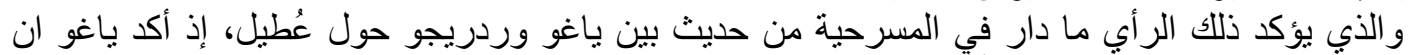

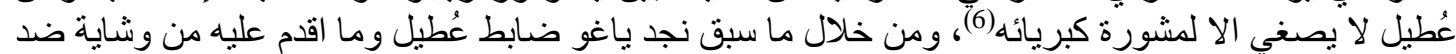

بعد مرتكز عصر النهضة. ير اجع للمزيد من التفاصيل. جيري بروتون، عصر النهضة، ترجمة. ابراهيم البيلي محروس،

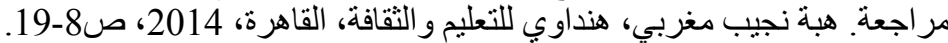

(1) Sidney Lee, A Life of William Shakespeare, Ed. 4, Smith Elder \& CO 15 Waterloo, London,1989, P.7-8;

عباس محمود العقاد، التعريف بشكسبير، مؤسسة هنداوي للتعليم و التقافة، القاهرة،2013، ص29 ص- 11. (2)Jose Manuel Gonzalez, Op. Cit, P.295.

(3) نادر ظاهر، تحليل ونقد مسرحية عطيل لشكسبير، دنيا الوطن(مجلة)، القاهرة، آب. 2012.

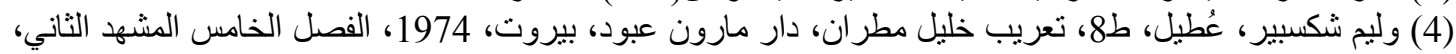
Richard F. Burton, Op .cit. 


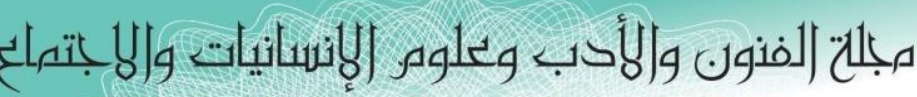
Journal of Arts, Literature, Humanities and Social Sciences

ISSN online: 2414 - 3383

ديسمبر 2019

ISSN print: 2616 - 3810

Volume (47)

العدد (47)

December 2019

ديدمونة زوج عُطيل، ما كان دافعه الا حبه لديدمونة الذب ولد لديه الحقد و الكر اهية لعُطيل وار اد ان ينتقم منه،

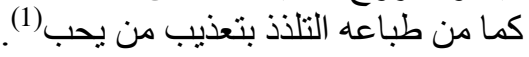

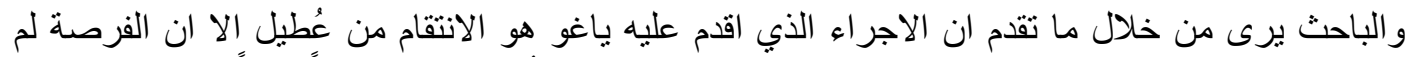

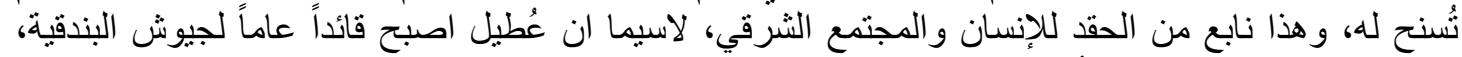

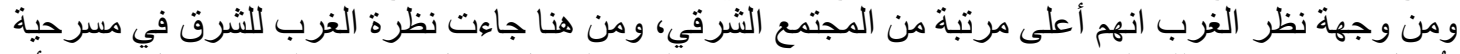

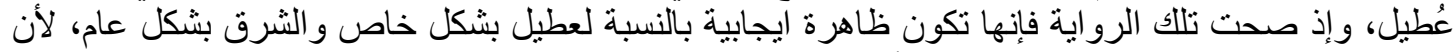

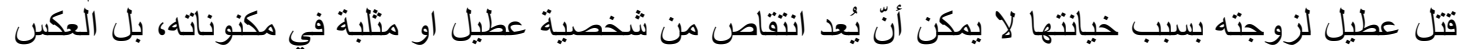

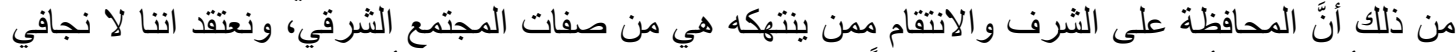

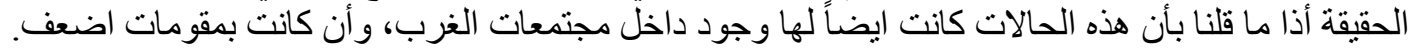

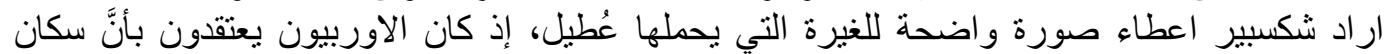

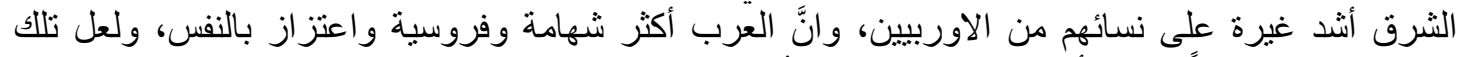

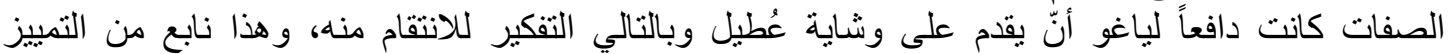

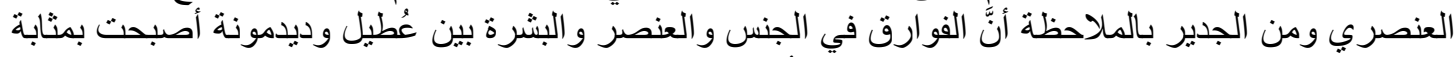

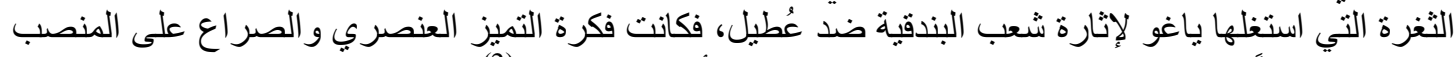

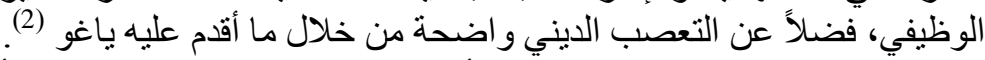

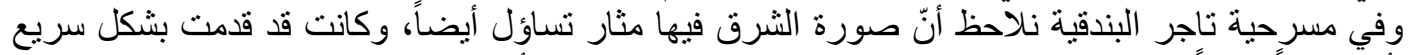

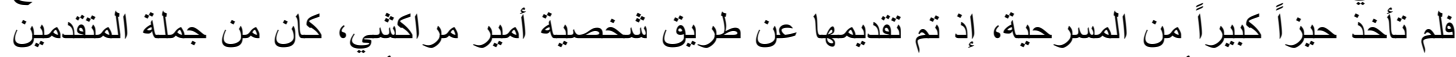

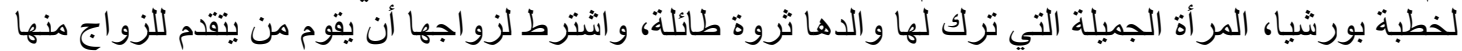

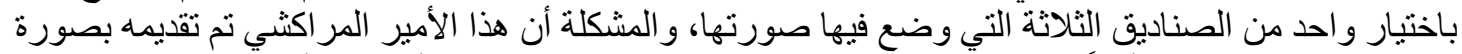

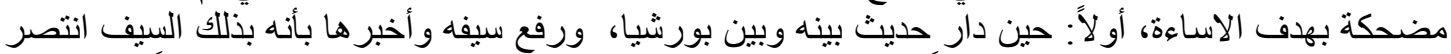

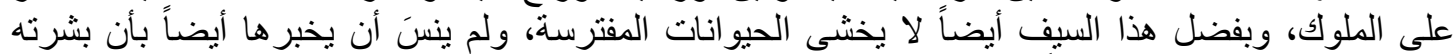

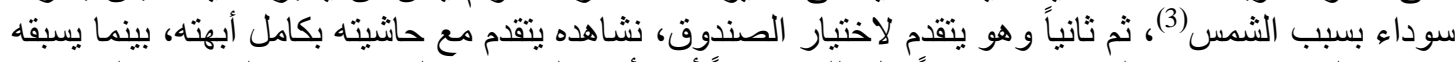

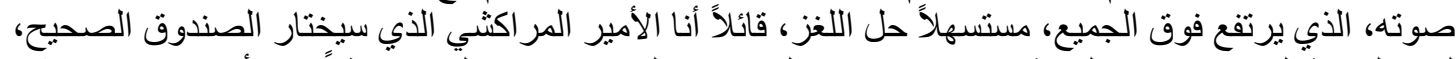

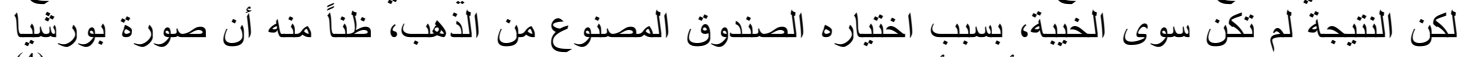

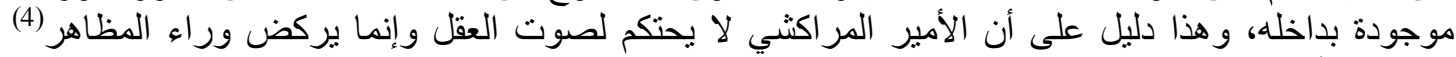

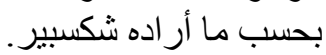

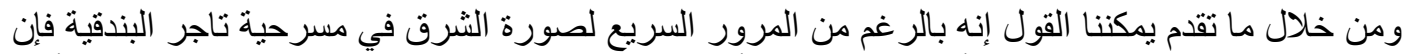

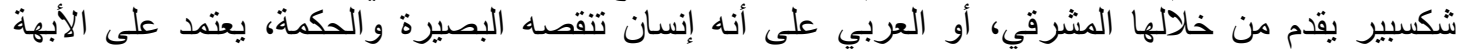

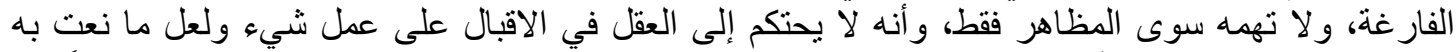

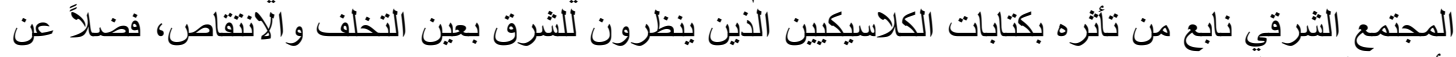
تأثره بالديانة المسيحية.

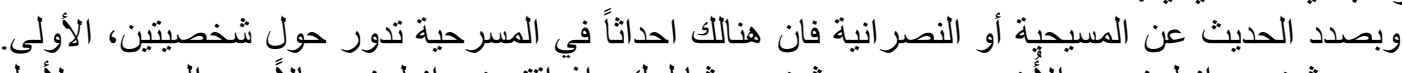

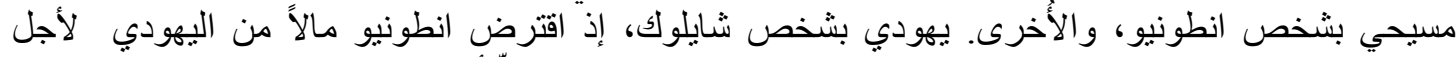

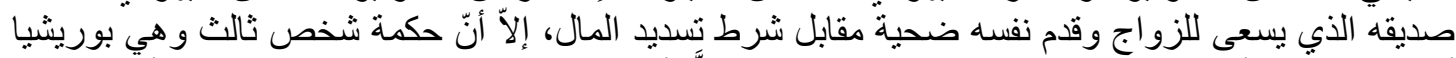

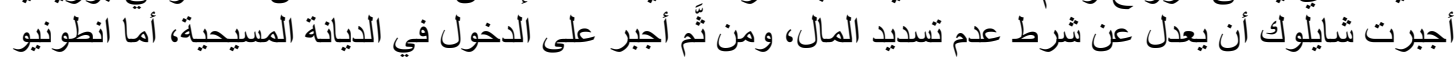

A. C. Bradley, Shakespearean Tragedy, The Noonday, NO .D, P. 179.

(1) نادر ظاهر، تحليل ونقد مسرحية عطيل لثكسبير، دنيا الوطن(مجلة)، القاهرة، آب. 2012. يراجع المسرحية لوليم

A. C. Bradley, Op . Cit, P. 180.

شكسبير، الفصل الثالث ـ المشهد الثاني؛

(2) سامي عبد الحميد، العرب في مسرح شكسبير دراسة مقارنة للمقاربتين النصية والاخر اجية، اطروحة دكتور اه غير

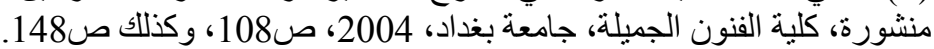

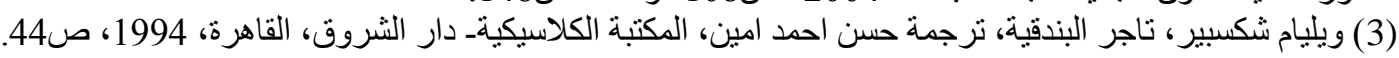

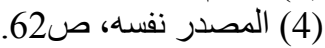




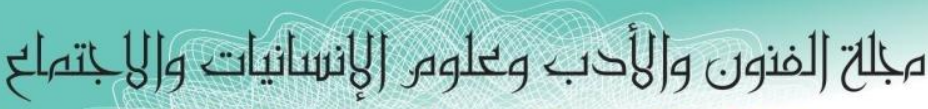
Journal of Arts, Literature, Humanities and Social Sciences

ISSN online: 2414 - 3383

ISSN print: 2616 - 3810
2019 ديسمبر

Volume (47)
(47) العدد (201)

December 2019
LALLHSS www.jalhss.com

وصديقه وبوريشيا فقد غمر هما الفرح وحب الآخرين(1)، وتناقش تللك المسرحية قضية مأساوية تتعلق بالاستغلال

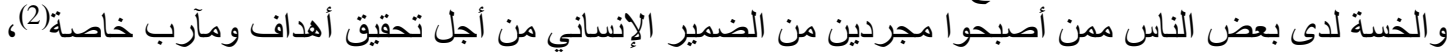

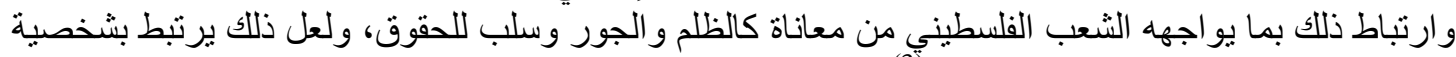

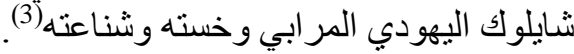

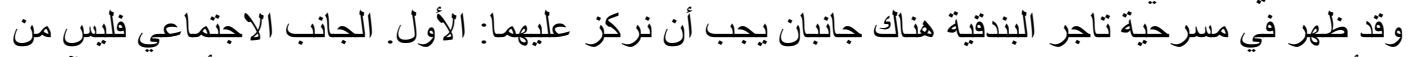

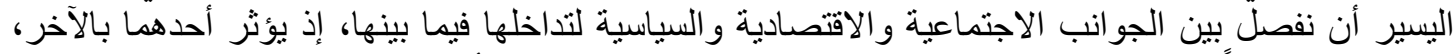

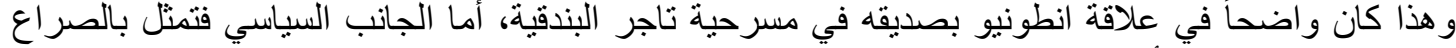

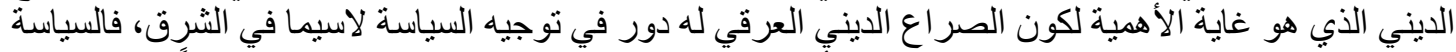

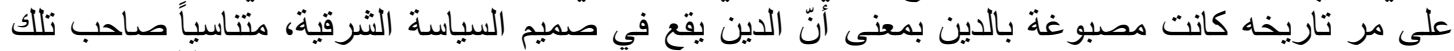

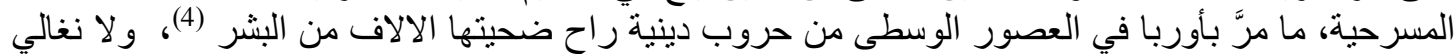

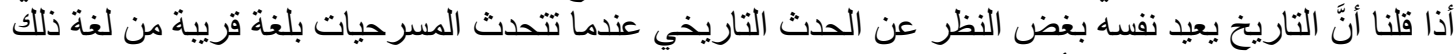

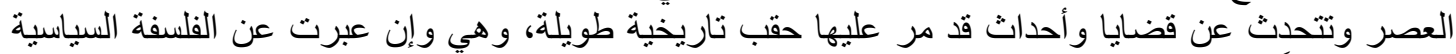

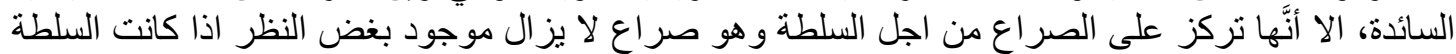

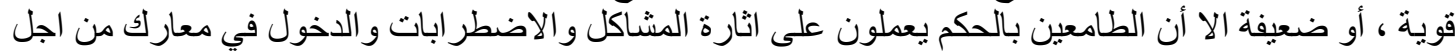

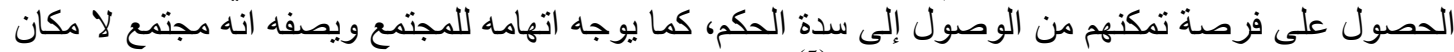

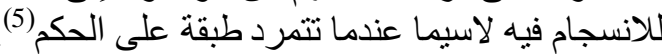

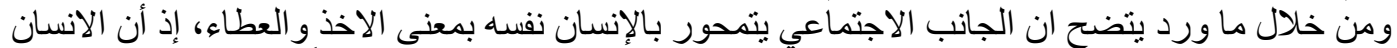

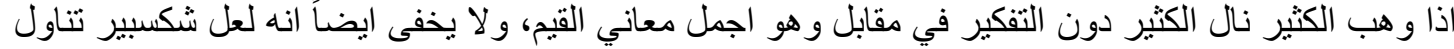

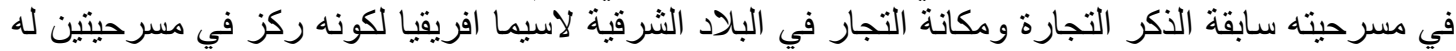

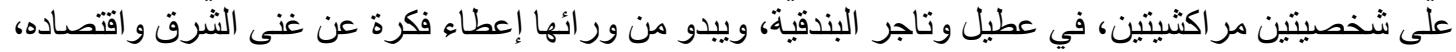

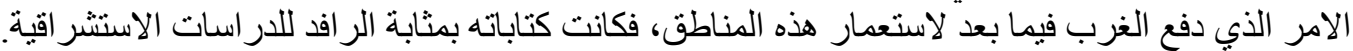

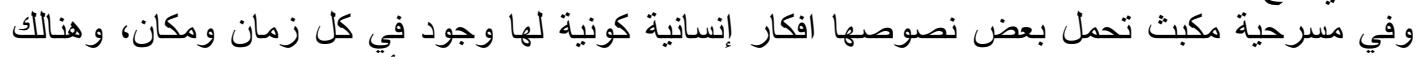

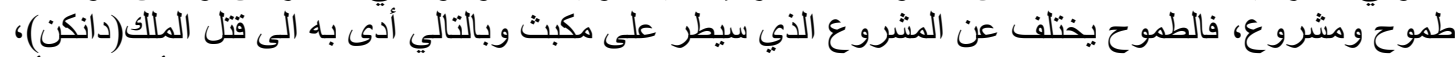

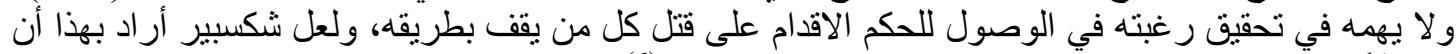

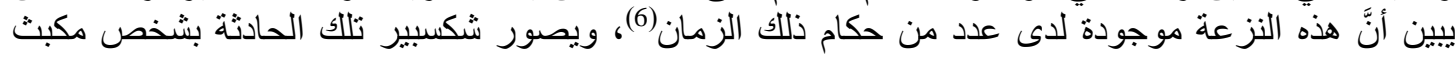

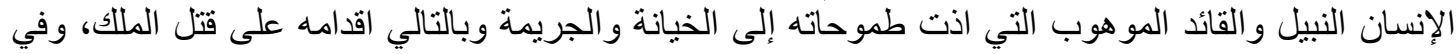

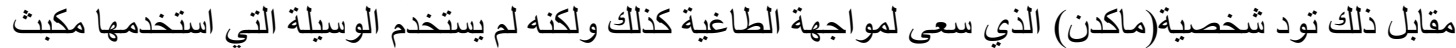

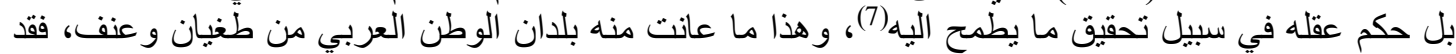

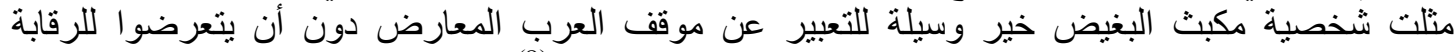

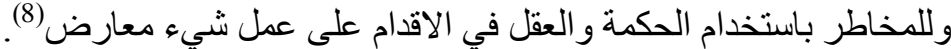

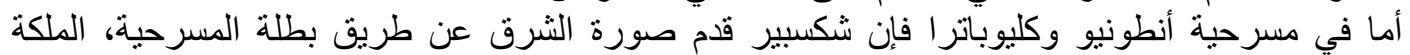

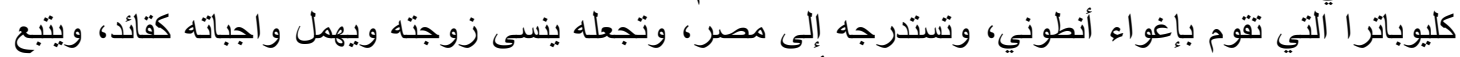

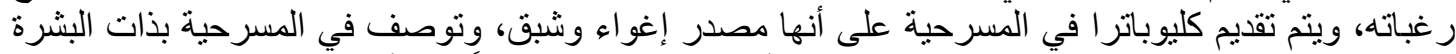

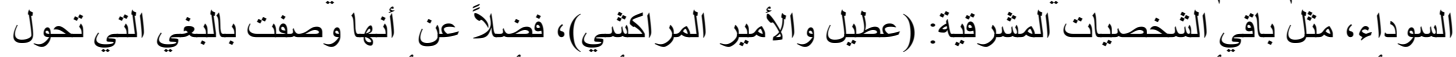
لديها أنطوني إلى أحمق، بينما يصفها الرومان بالغجرية، قائلين أن قلب أنطوني أصبح الوسائد و المروحة لتبريد التهيد

(1) علاء هاشُم، تاجر البندقية. لثكسبير: المسرحية المعضلة، الطريق(مجلة)، العدد 29، بيروت، كانون الاول، 2004.

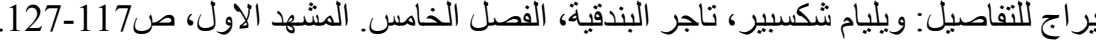

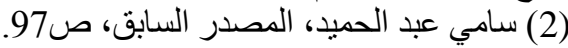

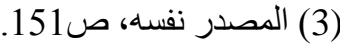

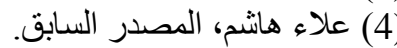

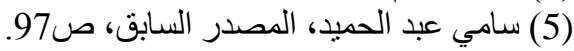

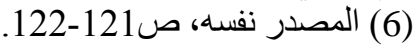

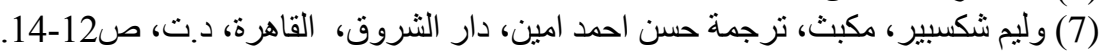

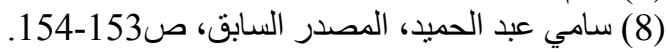


مبلحت (لفنون والأدب وعلوه الإنسانيات والبانتهاع

Journal of Arts, Literature, Humanities and Social Sciences

ISSN online: 2414 - 3383

ISSN print: 2616 - 3810

\section{9 دِيسمبر \\ Volume (47)}

(47) العدد)

December 2019

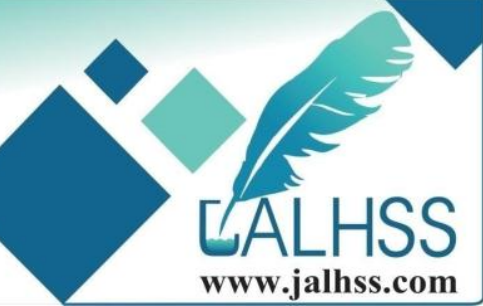

شبق الغجرية(1)، ويركز شكسبير على جمال كيلوباترا، وان ليس من الغريب ان يقع قياصرة روما في غلئ غرامها،

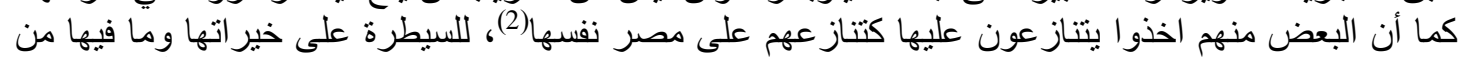

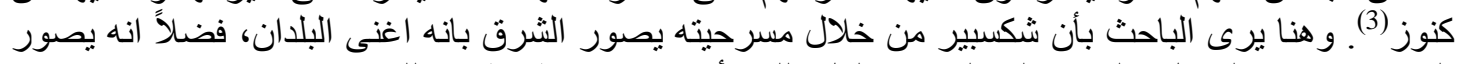

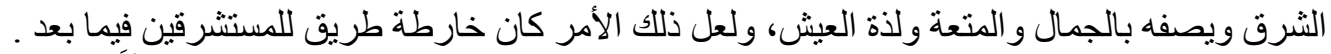

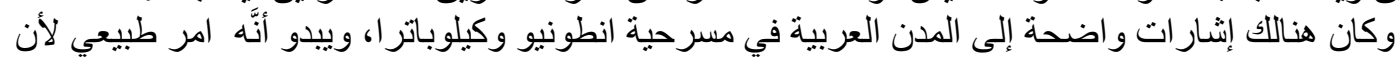

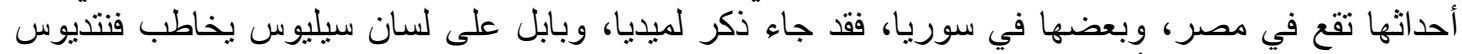

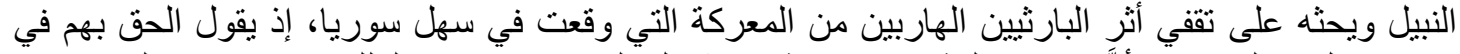

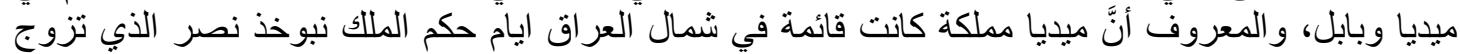

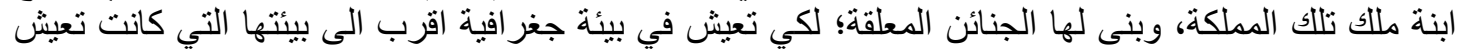

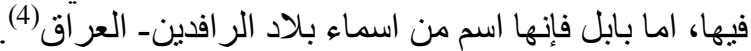

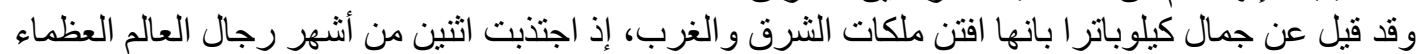

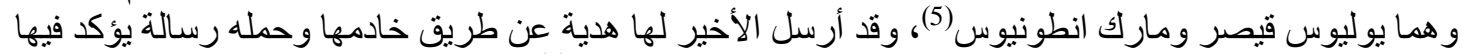

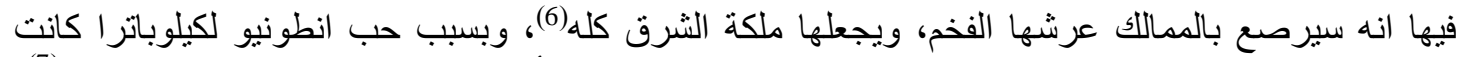

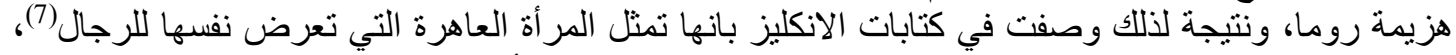

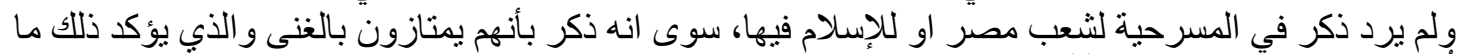

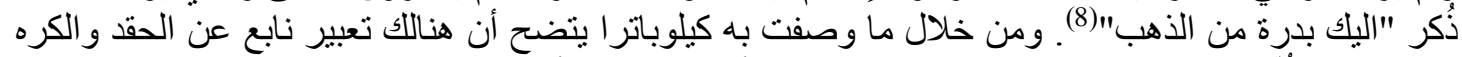

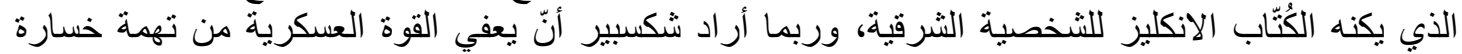

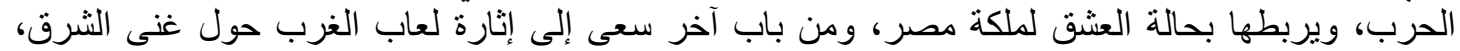
و وامكانية وضع اليد على ثرو اتهاه.

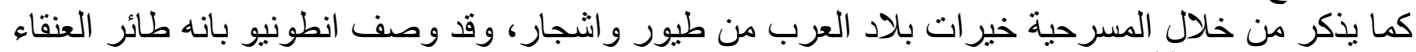

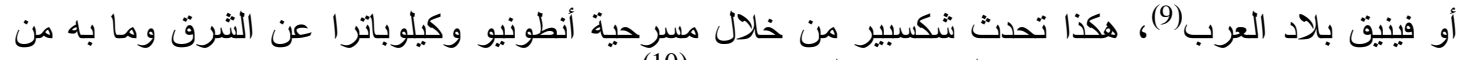

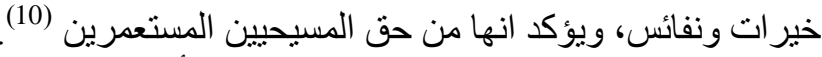

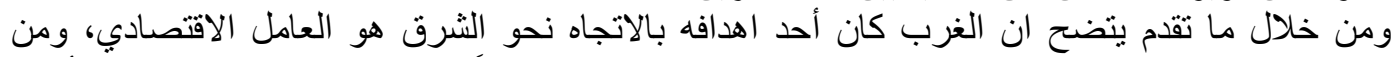

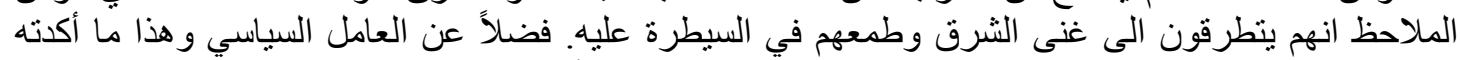

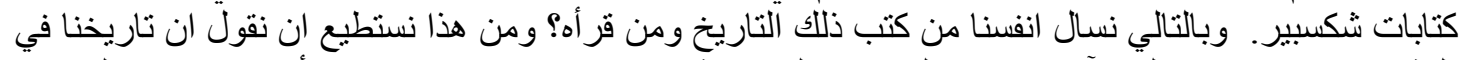

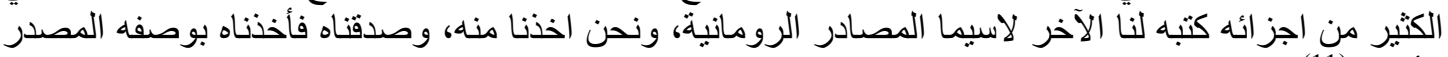
(الأساس (11).

(1) وليم شكسبير، انطونيوس و كيلو بطرة، ترجمة لويس عوض، دار الكاتب العربي للطباعة والنشر، القاهرة، 1968،

WWW. Al-Hayat. Com. 2014) ابر اهيم العريس، انطونيو وكيلو باترا: الحب يهزم الحرب، الحياة (مجلة)،

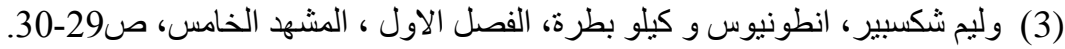

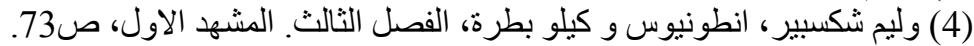

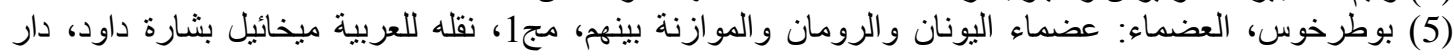

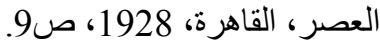

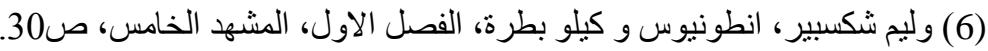

WWW. Al-Hayat. ابر اهيم العريس، انطونيو وكيلو باتر ا، الحب يهزم الحرب، الحياة (مجلة)،

(8) وليم شكسبير، انطونيوس و كيلو بطرة، الفصل الثالث، المشهـ الثالث، ص81-74.

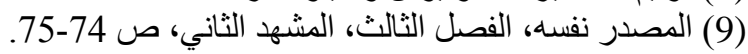

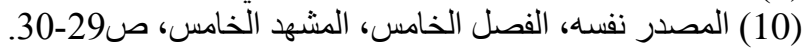

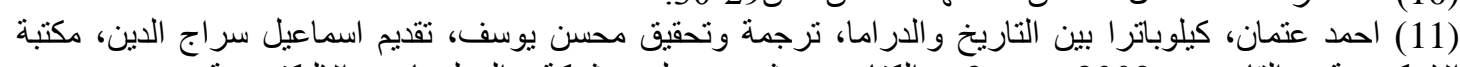

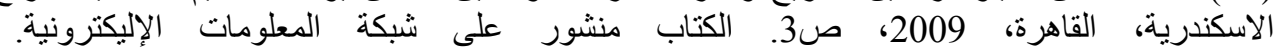
www.neelwafurat.com/itempage. 


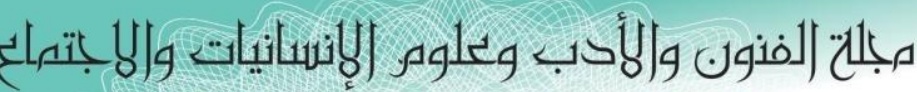

Journal of Arts, Literature, Humanities and Social Sciences

ISSN online: 2414 - 3383

ISSN print: 2616 - 3810

\section{9 دِيسوبر \\ Volume (47)}

(47) العدد)

December 2019

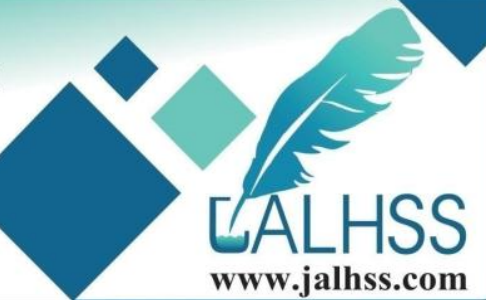

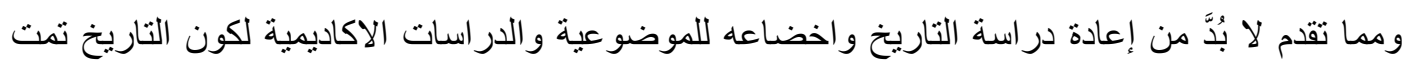

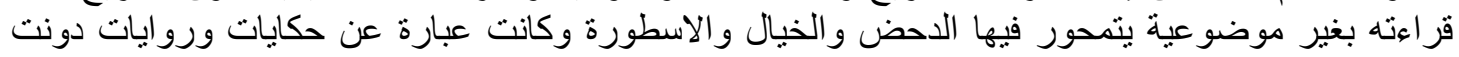

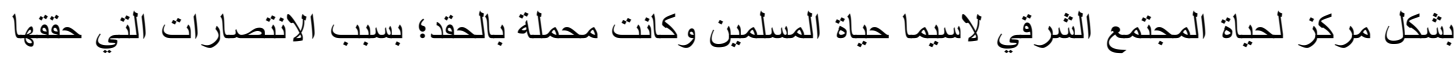

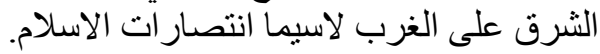

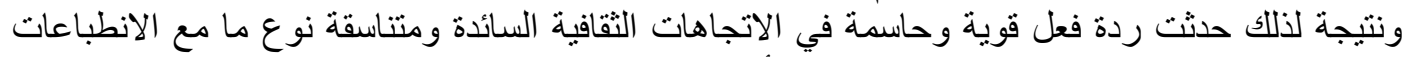

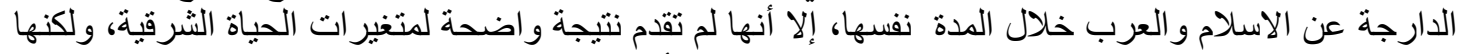

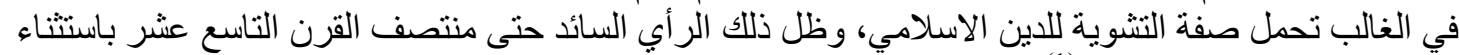

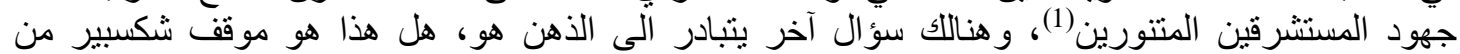

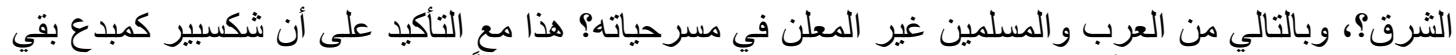

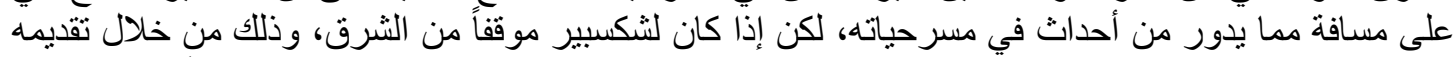

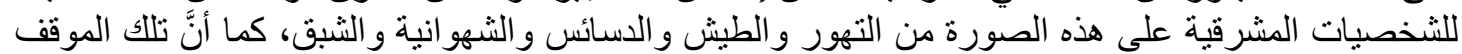

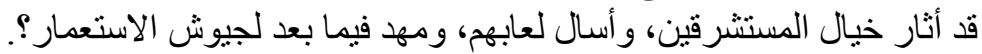

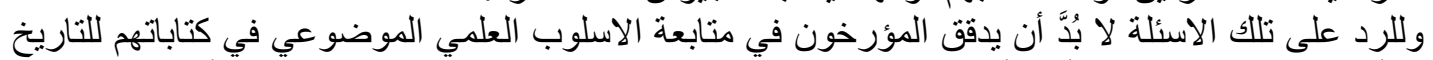

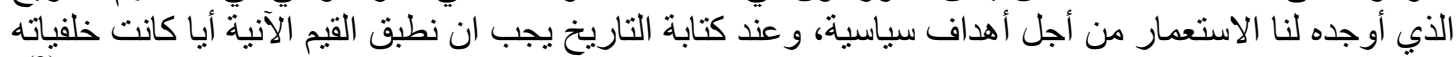

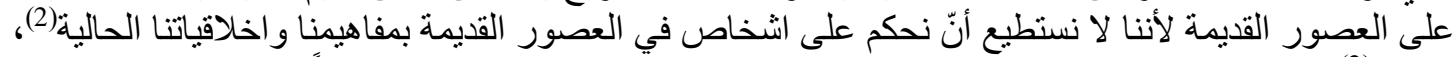

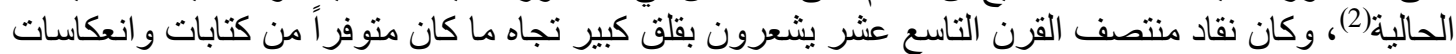

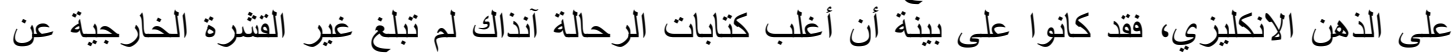

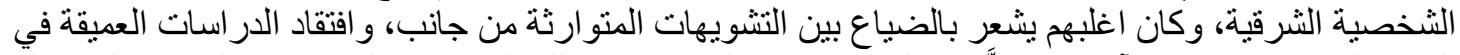

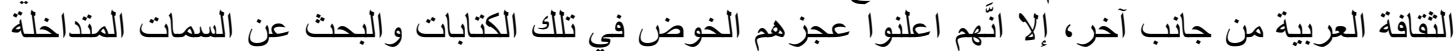

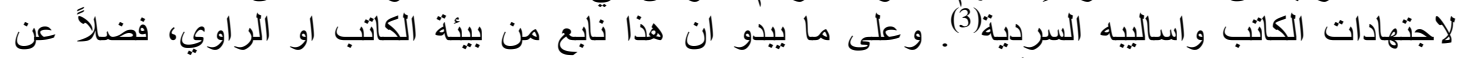

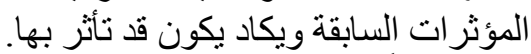

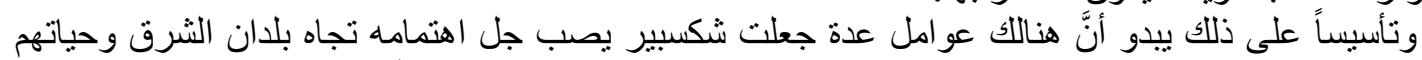

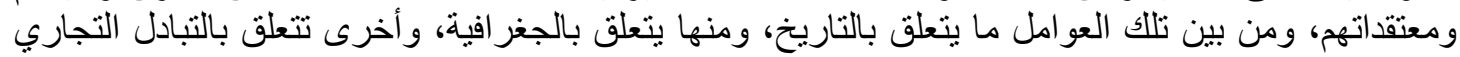

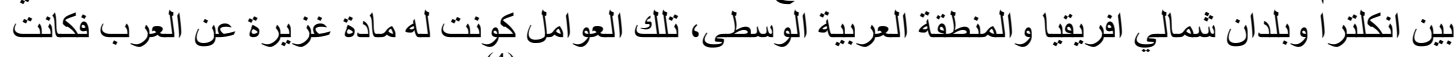

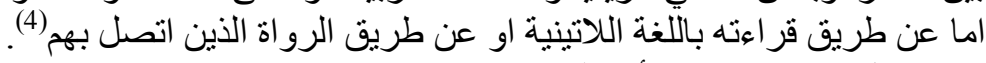

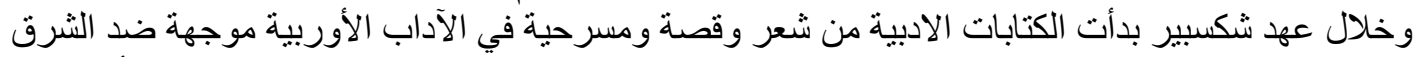

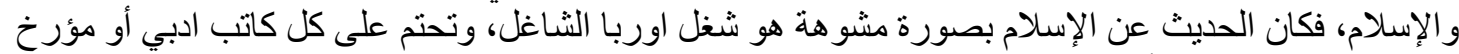

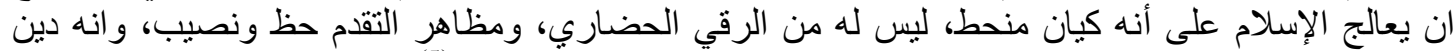

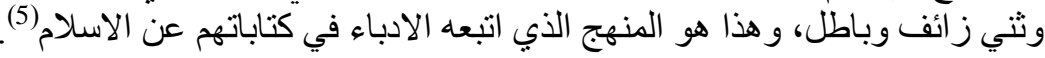

ثالثاً: صورة الإسلام في مسرحيات شكسبيز الإني

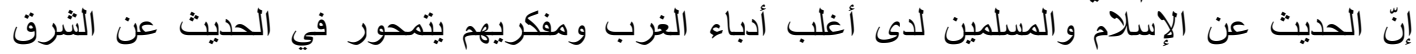

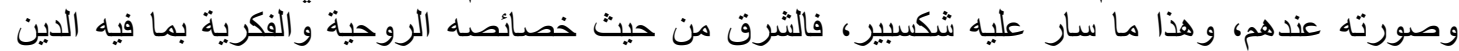

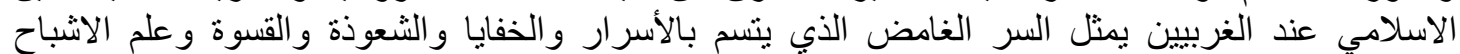

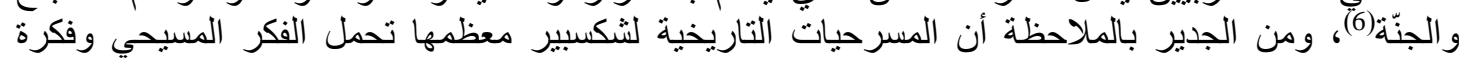

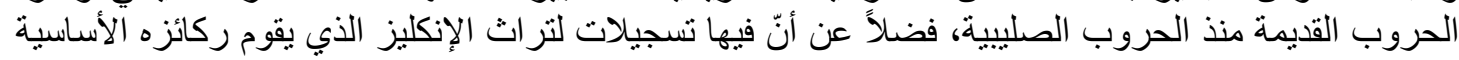

(1) محسن جاسم الموسوي، الوقوع في دائرة السحر الف ليلة وليلة في النقد الادبي الانكليزي1704-1910، دار الرشيد

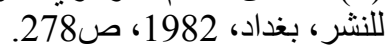

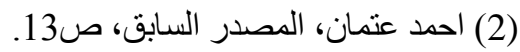

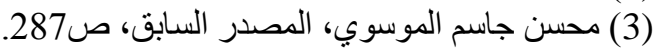

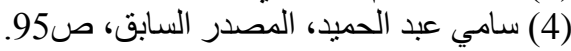

/http://www.al-sunna.net.

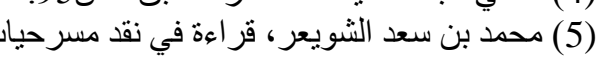
(6) عدنان محمد عبد العزيز وزان، فكر التتصبر في مسرحيات شكسبير، دار اثبيليا للنشر والتوزيع، جامعة ام القرى، 
مبلحت (لفنون والأدب وعلوه الإنسانيات والبانتهاع

Journal of Arts, Literature, Humanities and Social Sciences

ISSN online: 2414 - 3383

ISSN print: 2616 - 3810

\section{ديسمبر 2019 \\ Volume (47)}

العدد (47)

December 2019

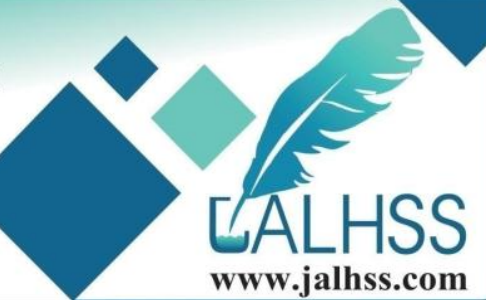

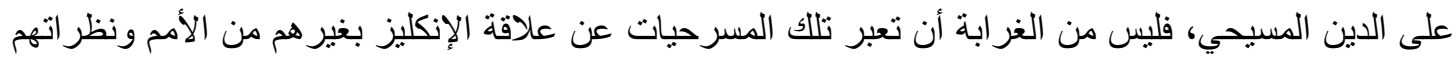

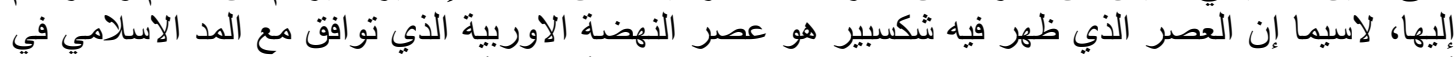

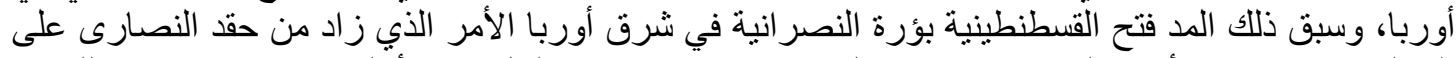

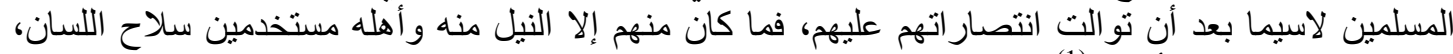

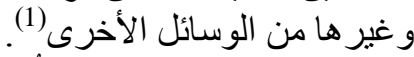

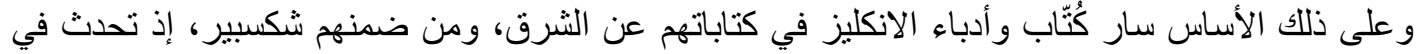

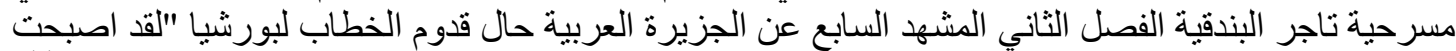

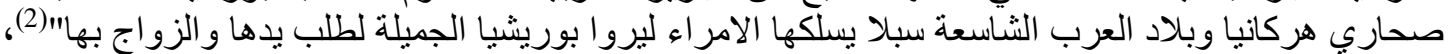

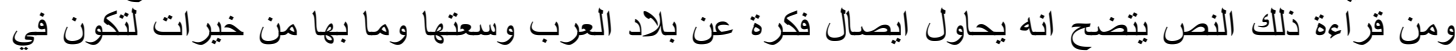

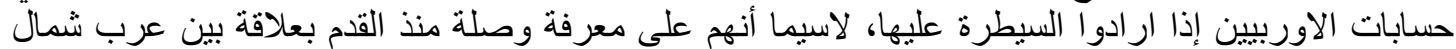
افريقيا وبين الإيطاليين عن طريق الذابن التجارة.

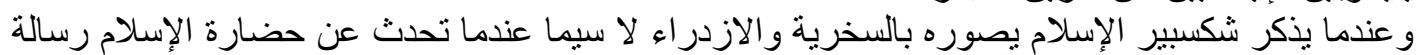

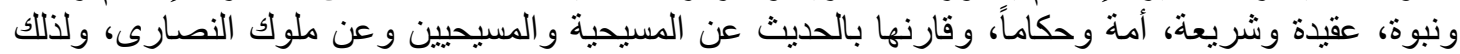

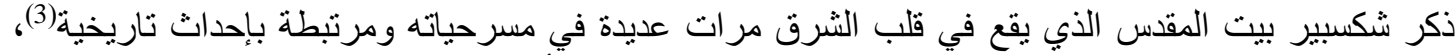

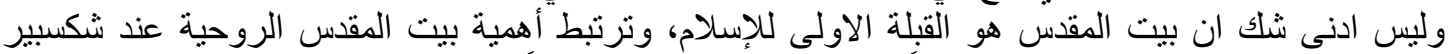

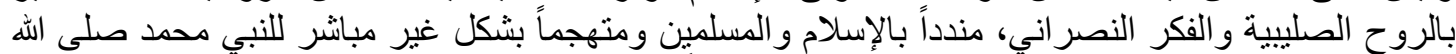

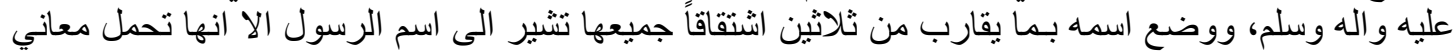

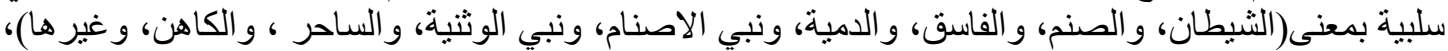

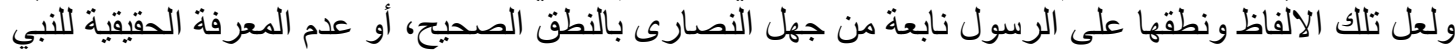

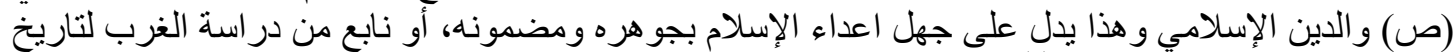

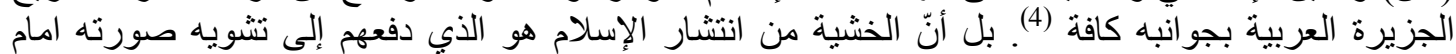

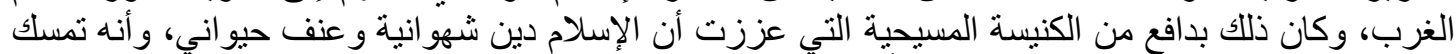

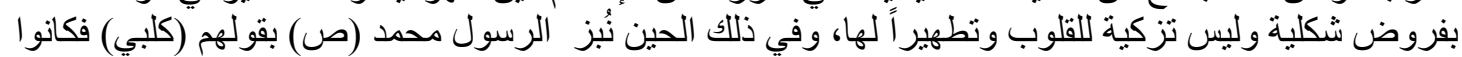

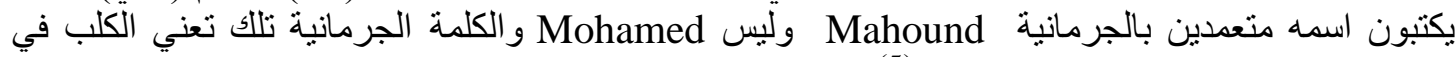

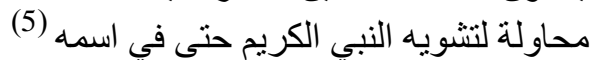
شمل شكسبير في مسرحية هنري الر ابع حب الوبي الوطن، إذ يتحدث فيها هوتسبر Hotspur في المعركة الحربية ضد الملك هنري الرابع Henry IV

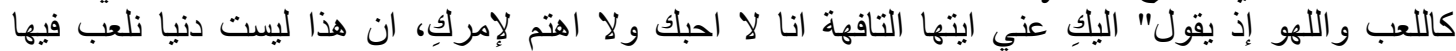

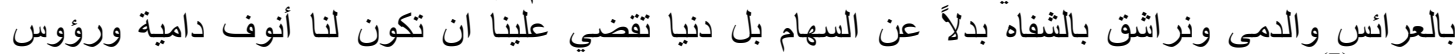

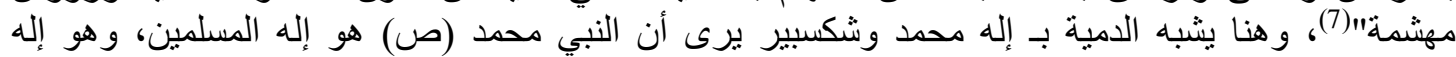

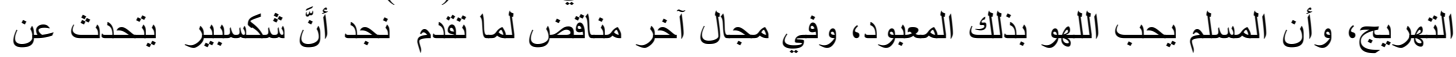

(1) عدنان محد عبد العزيز وزان، صورة الاسلام في الادب الانكليزي، دار انشيليا للنشر والتوزيع، الرياض، 1998،

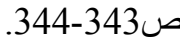

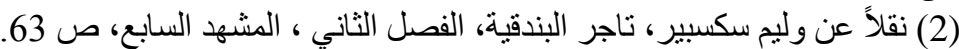

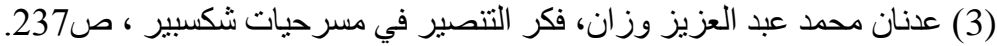

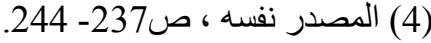

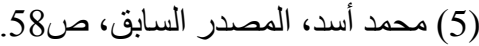

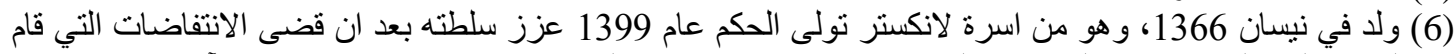
بها النبلاء، لكنه لم يوفق في السيطرة على الامور الادارية، وكانت السبب في نهاية حكمه، توفي في آذار 1413. 14انئ يراج

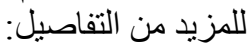
APA Style, Henry IV, Encyclopedia Britannica Ultimate Reference Suite. Chicago: Encyclopedia Britannica, 2010.

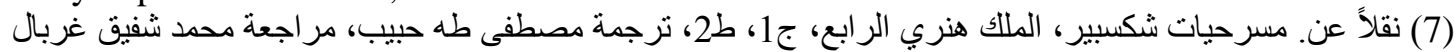

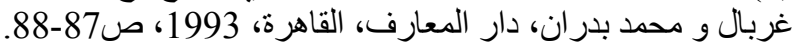




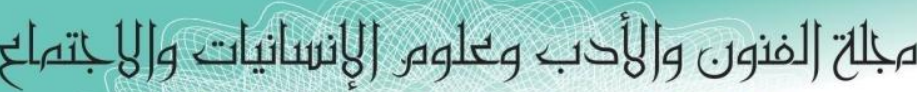

Journal of Arts, Literature, Humanities and Social Sciences

ISSN online: 2414 - 3383

2019 دِيسوبر

ISSN print: 2616 - 3810

Volume (47)

العدد (47)

December 2019

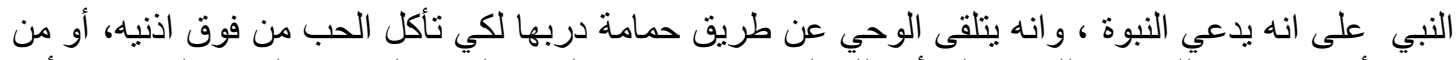

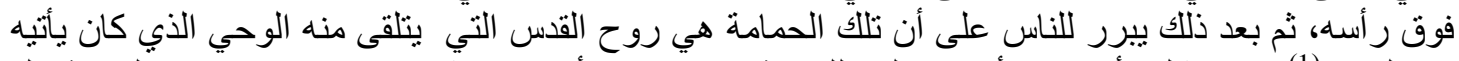

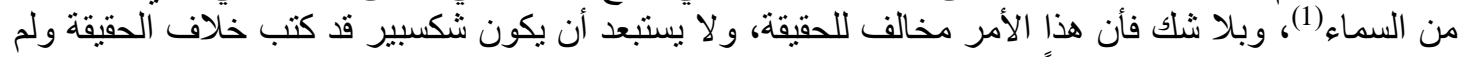

يغفل ذللك، بل كان يقصد مدفو عاً بغر ائزه الاستشر اقية.

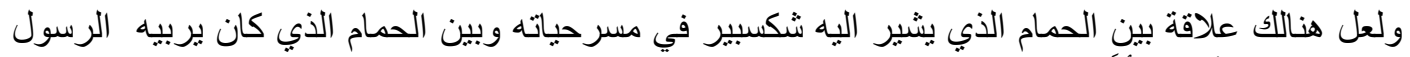

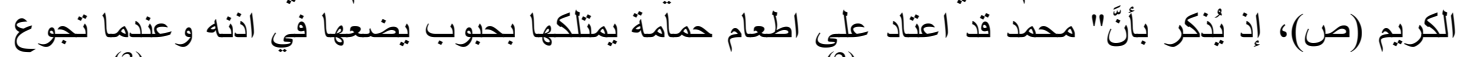

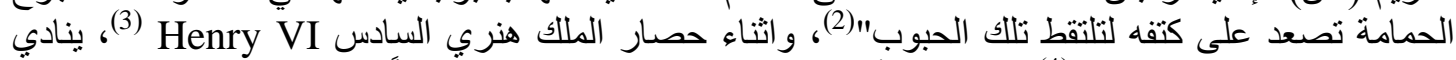

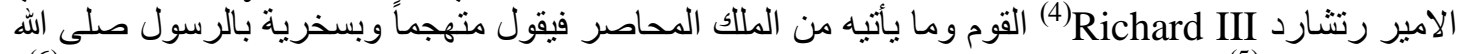

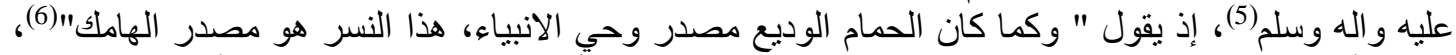

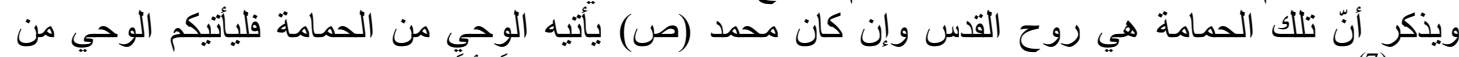

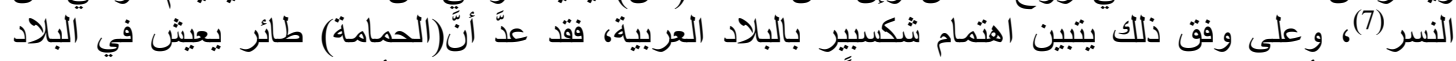

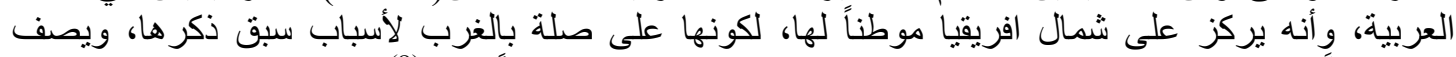

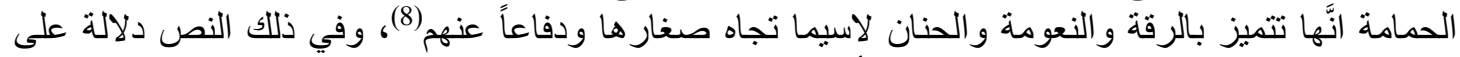

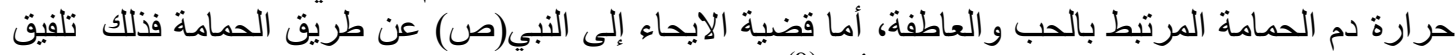

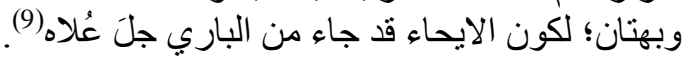

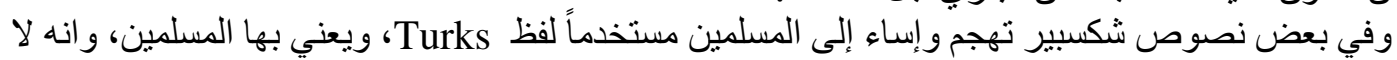

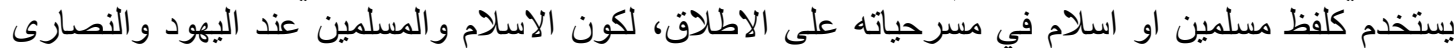

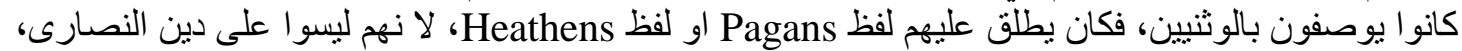

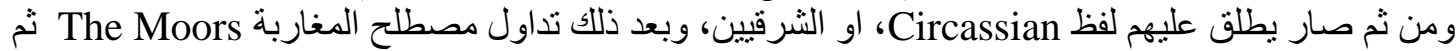

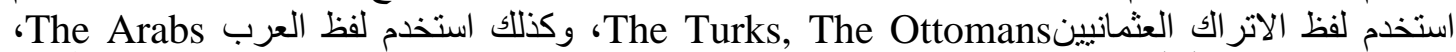

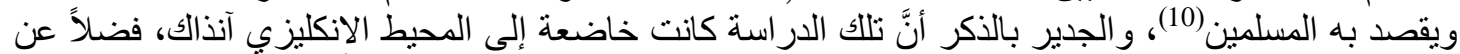

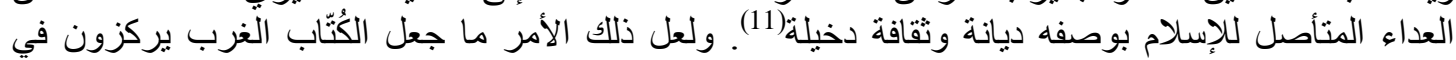

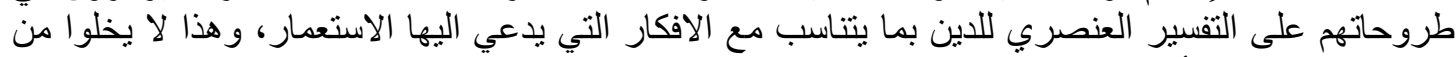

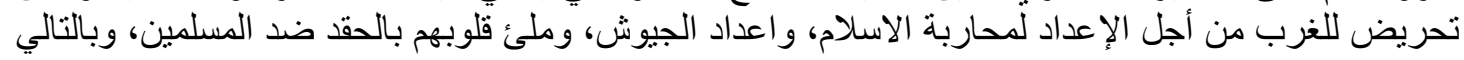

$$
\begin{aligned}
& \text { (1) عدنان محمد عبد العزيز وزان، فكر التنصبر في مسرحيات شكسبير ، ص245. }
\end{aligned}
$$

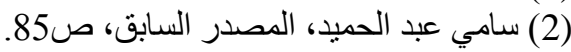

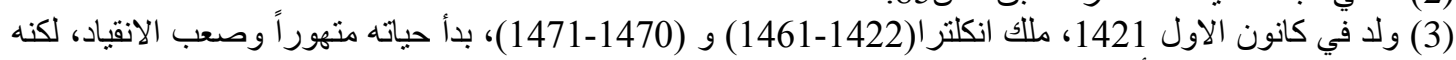

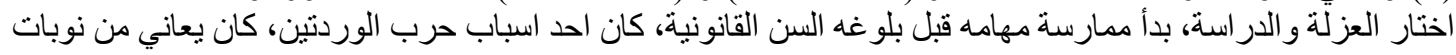

جنون، توفي في ايار 1471.

MLA Style, "Henry VI.", Encyclopedia Britannica Ultimate Reference Suite. Chicago: Encyclopedia Britannica, 2010.

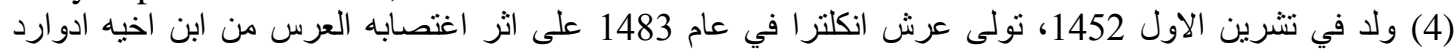

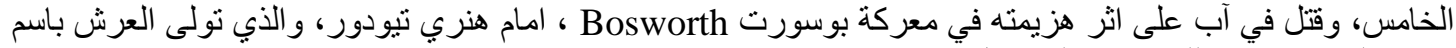
هنري السابع. ير آجع للمزيد من التفاصيل:

The standard biography of the king is Charles Ross, Richard III, Encyclopedia Britannica, 2010.

(5) عدنان محمد عبد العزيز وزان، فكر التتصير في مسرحيات شكسبير ، ص245.

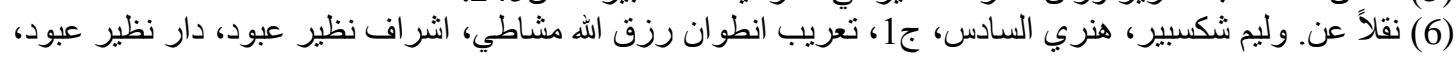

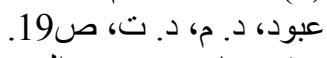$$
\text { (7) عدنان محمد عبد العزيز وزان، صدي، صورة الاسلام في الادب الانكليزي، ص3232. }
$$

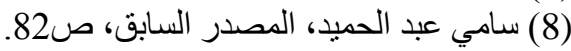

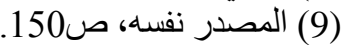

(10) نقلاً عن عدنان محمد عبد العزيز وزان، فكر التتصبر في مسرحيات شكسبير، ص246.

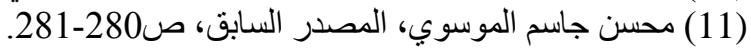




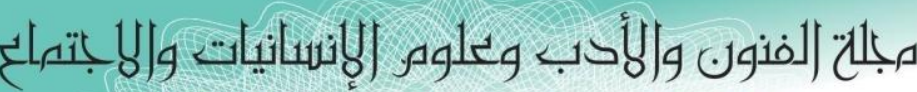

Journal of Arts, Literature, Humanities and Social Sciences

ISSN online: 2414 - 3383

ISSN print: 2616 - 3810

\section{9 دِيسوبر \\ Volume (47)}

(47) (4)

December 2019

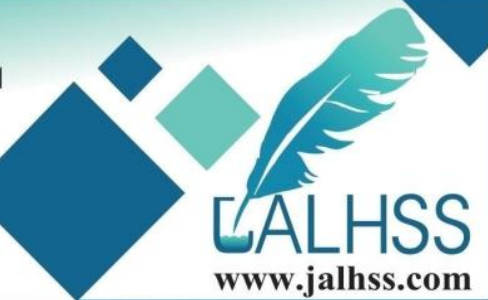

تكوين صورة مشوهة للإسلام حتى يتمكنوا من تفريغ محتواه العقائدي، وهم على علم المع بسمو تعاليم الإسلام

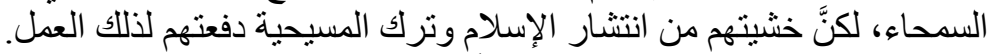

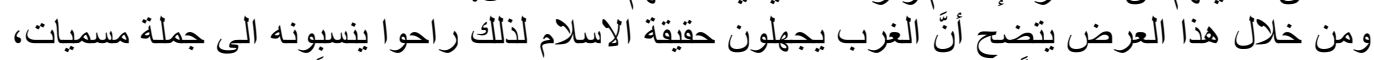

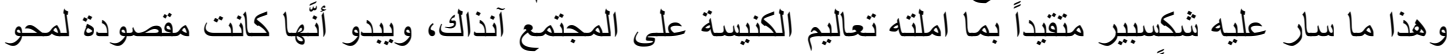

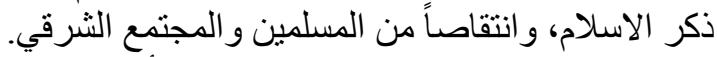

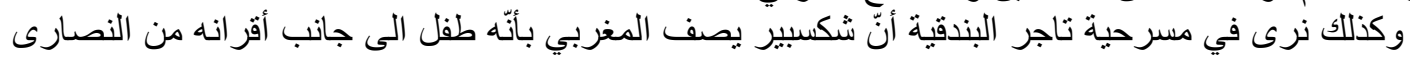

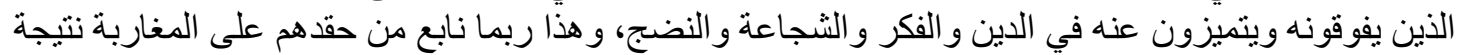

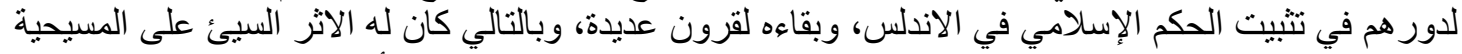

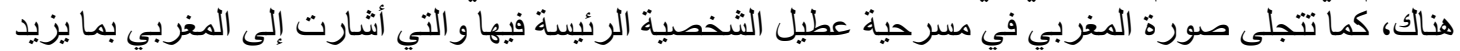

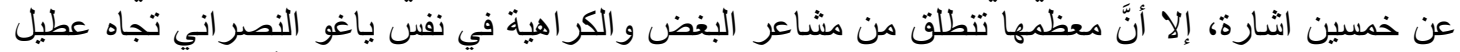

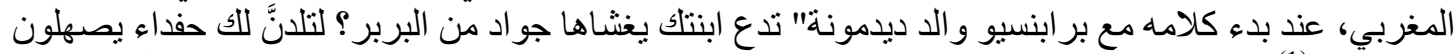

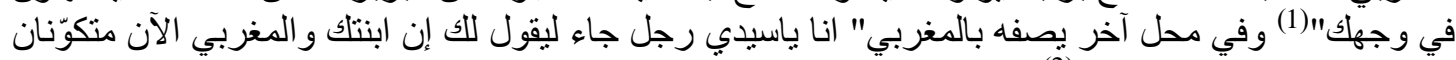

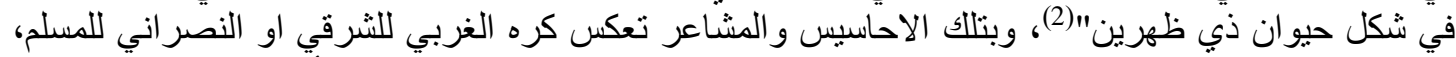

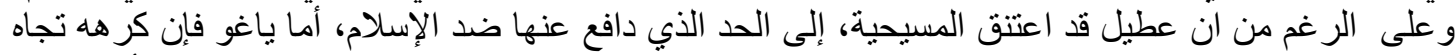

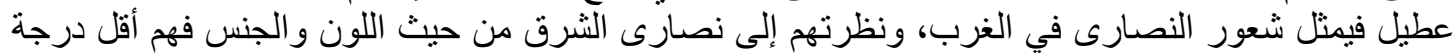

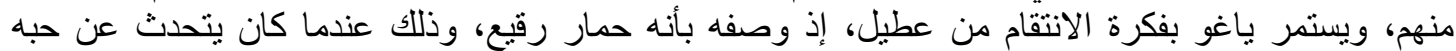

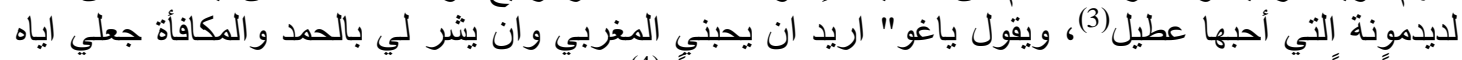

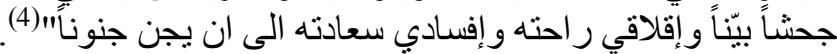

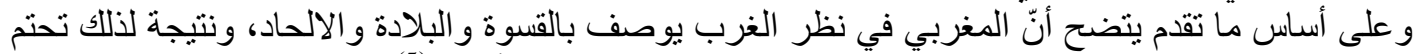

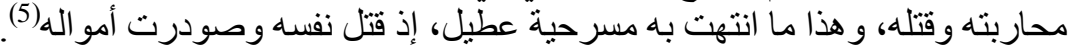

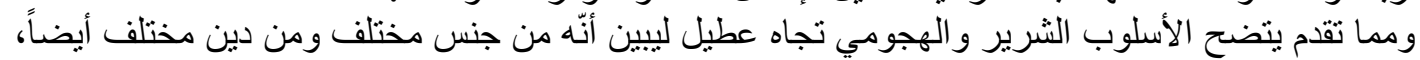

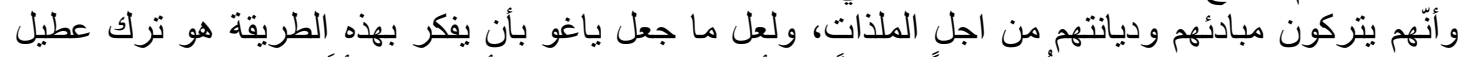

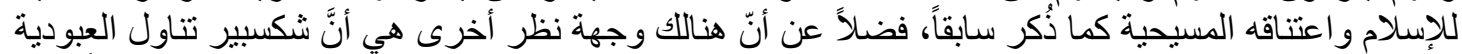

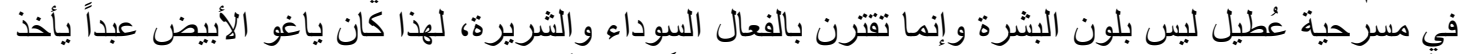

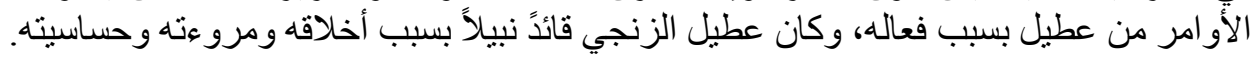

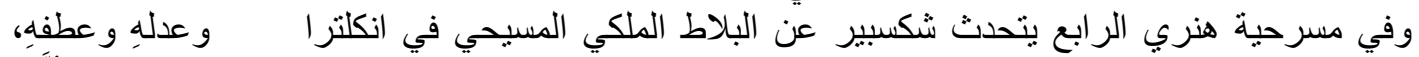

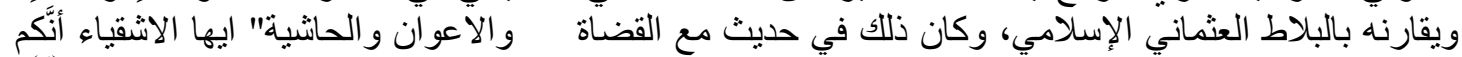

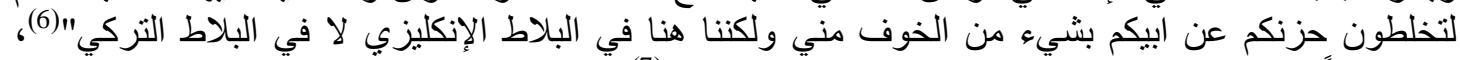

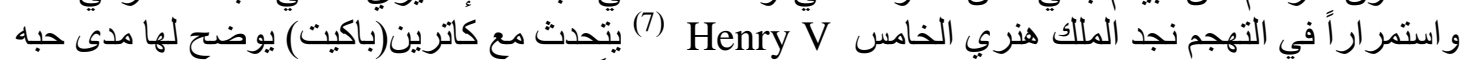

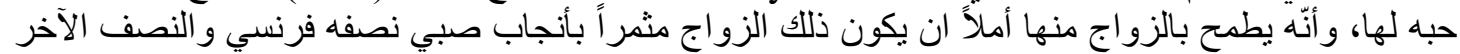

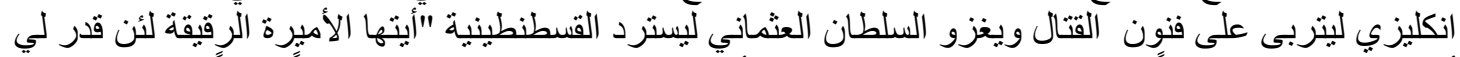

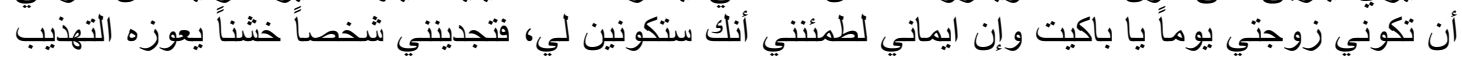

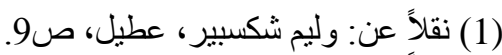

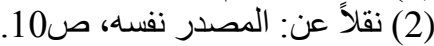

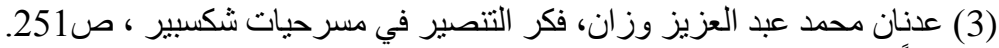

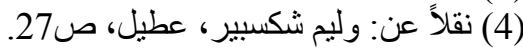

(58) ير اجع. عدنان محمد عبد العزيز وزان، فكر التصبير في مسرحيات شكسبير، ص253-254؛ وليم شكسبير، عطيل، A. C. Bradley, Op. Cit, P. 189.

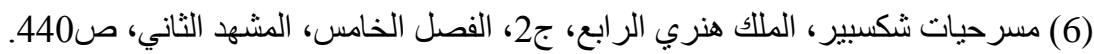

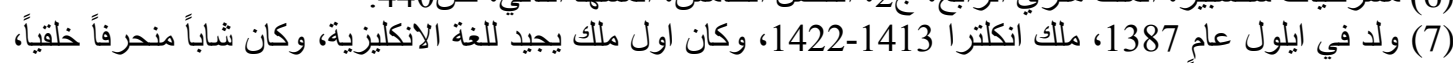

الا انه بعد آن توج ملكاً تحول في سلوكه، ونوفي في اب 1422. ير اجع للمزيد من التفاصيل:

C.L. Kingsford, Henry V: The Typical Mediaeval Hero, Encyclopedia Britannica Ultimate Reference Suite. Chicago: Encyclopedia Britannica, 2010. 


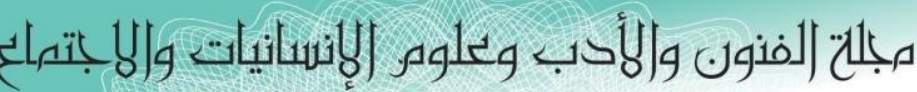

Journal of Arts, Literature, Humanities and Social Sciences

ISSN online: 2414 - 3383

ISSN print: 2616 - 3810
ديسمبر 2019

Volume (47)
(47) (4) (العدد)

December 2019

\section{¿ALHSS} www.jalhss.com

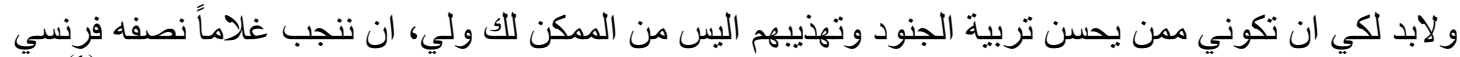

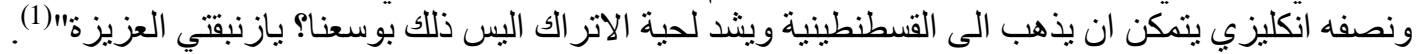

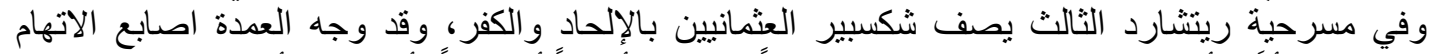

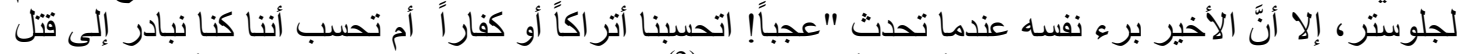

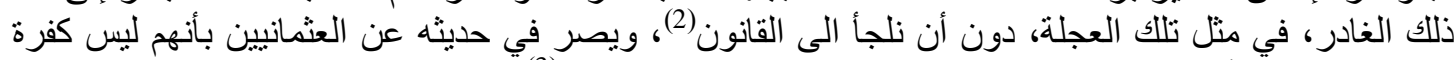

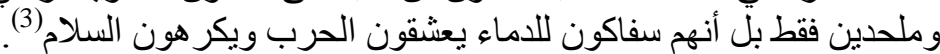

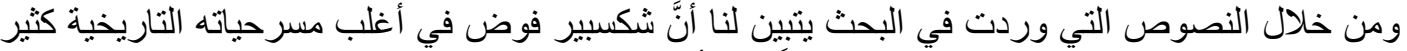

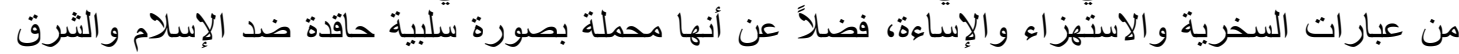

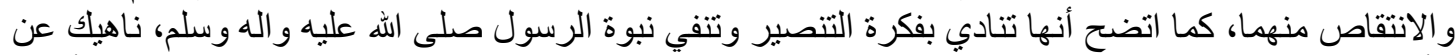

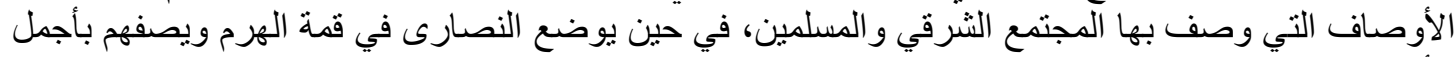

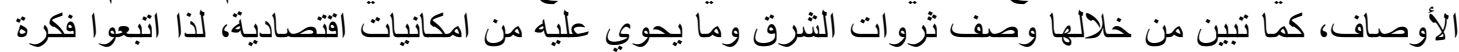

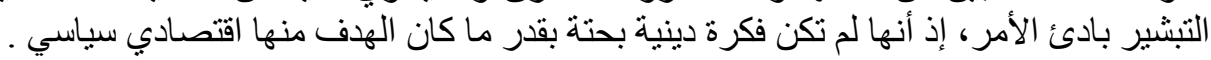

الخاتمة

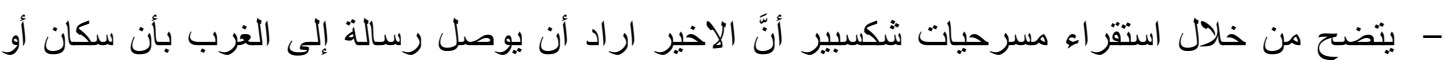

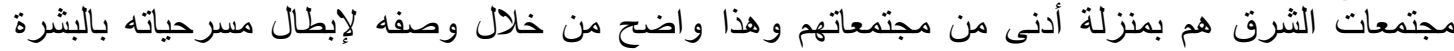

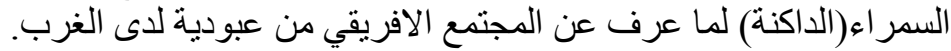

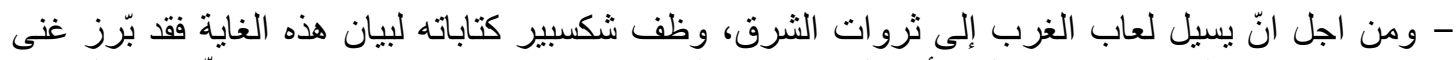

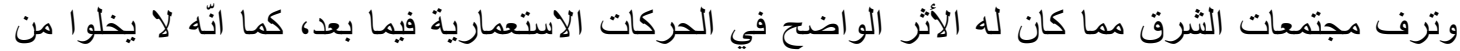

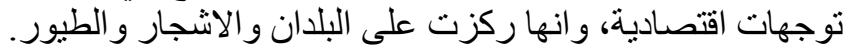

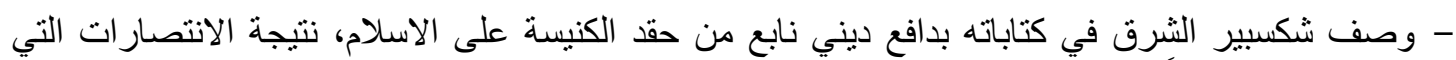

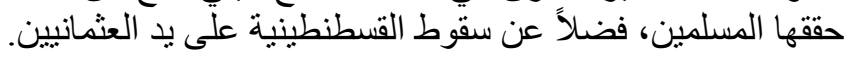

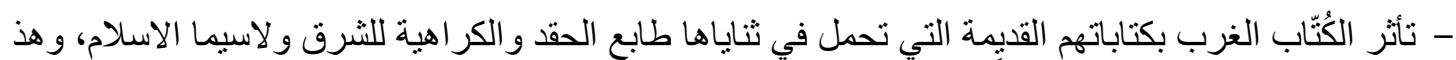

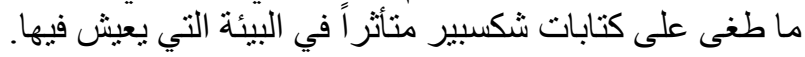

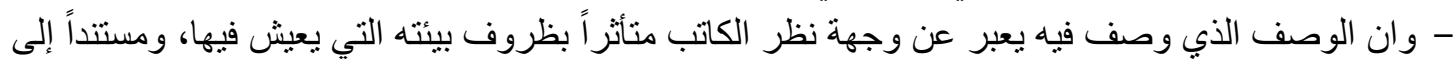

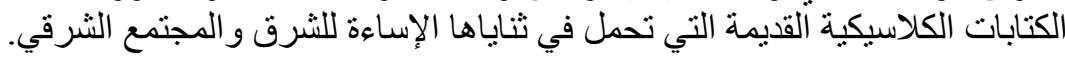

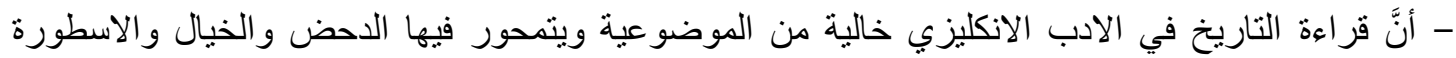

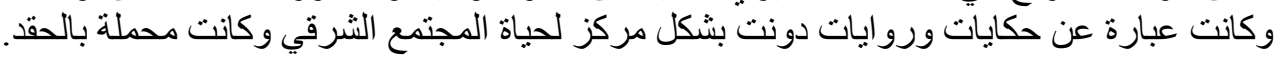

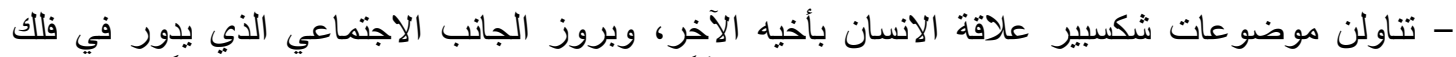

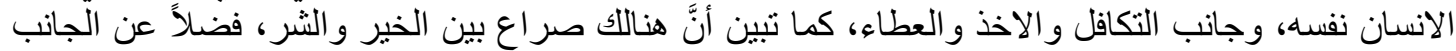

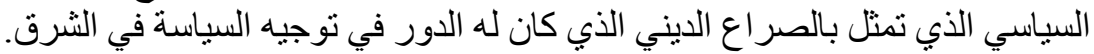

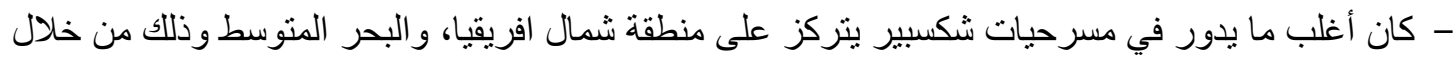

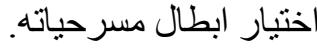

(1) نقلاً عن: مسرحيات شكسبير، هنري الخامس، ترجمة. محمد عوض محمد، مراجعة. محمد شفيق غربال و محمد

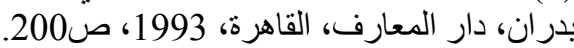

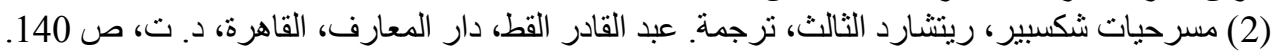

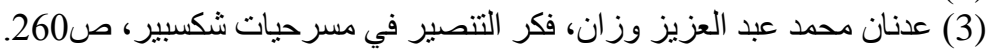




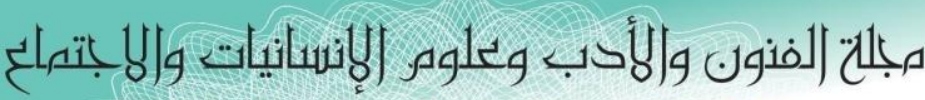
Journal of Arts, Literature, Humanities and Social Sciences

ISSN online: 2414 - 3383

ISSN print: 2616 - 3810
ديسمبر 2019

Volume (47)
(47) العدد

December 2019

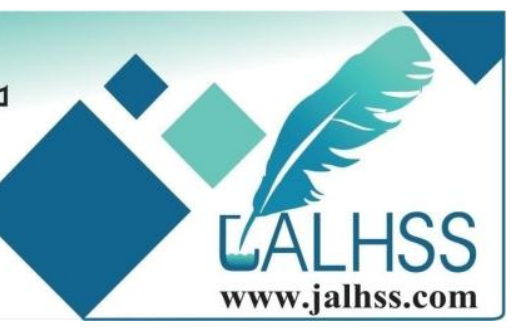

المصادر العربية المابة

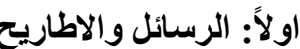

1- سامي عبد الحمبد، العرب في مسر حسئ شكسبير در اسة مقارنة للمقاربنين النصية والاخر اجية، اطروحة دكتور اه غير

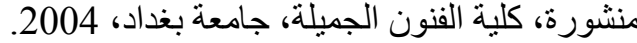
ثانياً: الكتب العربية وانية والمعربة.

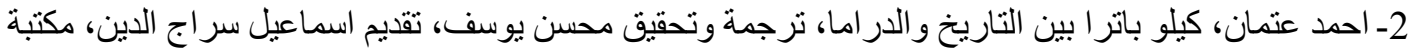

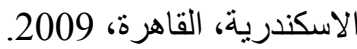

3- البرت حور اني، الاسلام في الفكر الاوربي، الاهلية، الألية للنشر والتوزيع، بيروت، 1994.

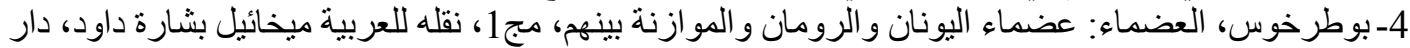
العصر ، القاهرة، 1928. 5- جيري بروتون، عصر النهضة، نرجمة، ابر اهيم البيلي محروس، مر اجعة. هبة نجيب مغربي، هنداوي للتعليم و الثقافة، القاهرة، 6- عباس محمود العقاد، التعريف بشكسبير ، مؤسسة هنداوي للتعليم و الثقافة، القاهرة،

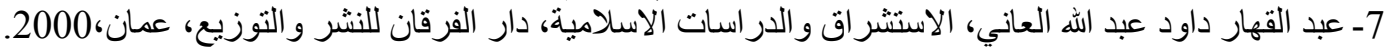

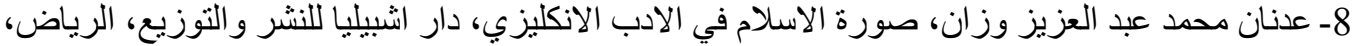

فكر التتصبر في مسرحيات شكسبير، دار اشبيليا للنشر والتوزيع، جامعة ام القرى، د.ت.

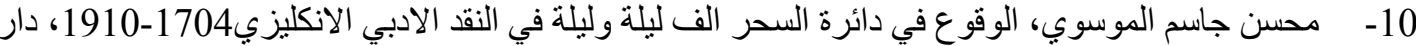
الرشيد للنشر ، بغداد، 1982.

11 - 12 - محمود حمدي زفزوق، 1982، الاسلام في تصور ات الغرب، مكتبة و هبة، القاهرة، 1987.

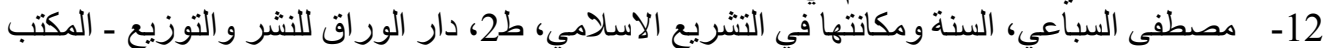
الاسلامي، د.م، 2000.

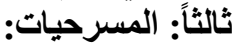

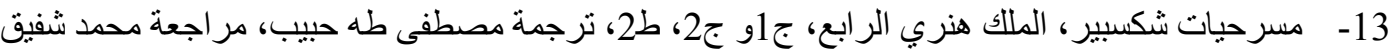

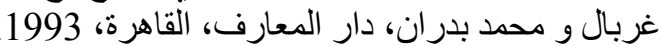

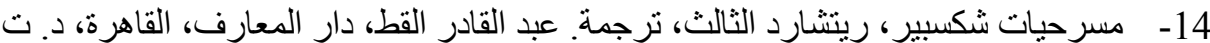

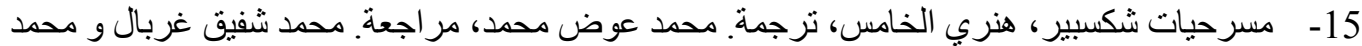
بدران، دار المعارف، القاهرة، 1993. 16- وليم شكسبير، انطونيوس و كيلو بطرة، ترجمة لويس عوض، دار الكاتب العربي للطباعة و النشر، القاهرة، .1968

17- وليم شكسبير، عُطيل، ط8، تعريب خليل مطران، دار مارون عبود، بيروت، 1974

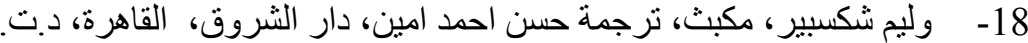

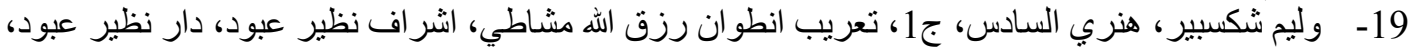

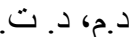
20- ويليام شكسبير، تاجر البندقية، ترجمة حسن احمد امين، المكتبة الكلاسيكيةـ دار الشروق، القاهرة، 1994. رابعاً: شبكة المعلومات الاليكترونية:

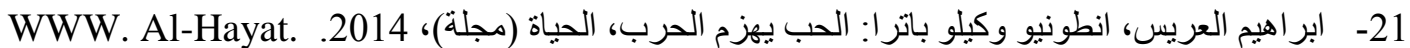
Com 22- علاء هاثم، تاجر البندقية. لشكسبير : المسرحية المعضلة، الطريق(مجلة)، العدد 29، بيروت، كانون الاول، 2004

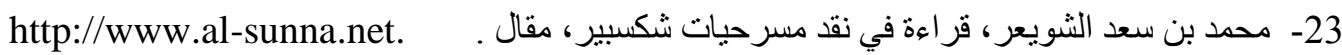

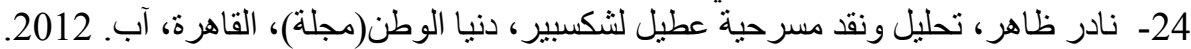

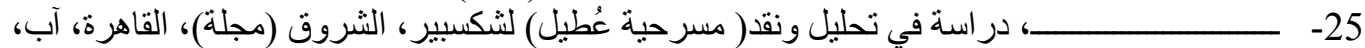




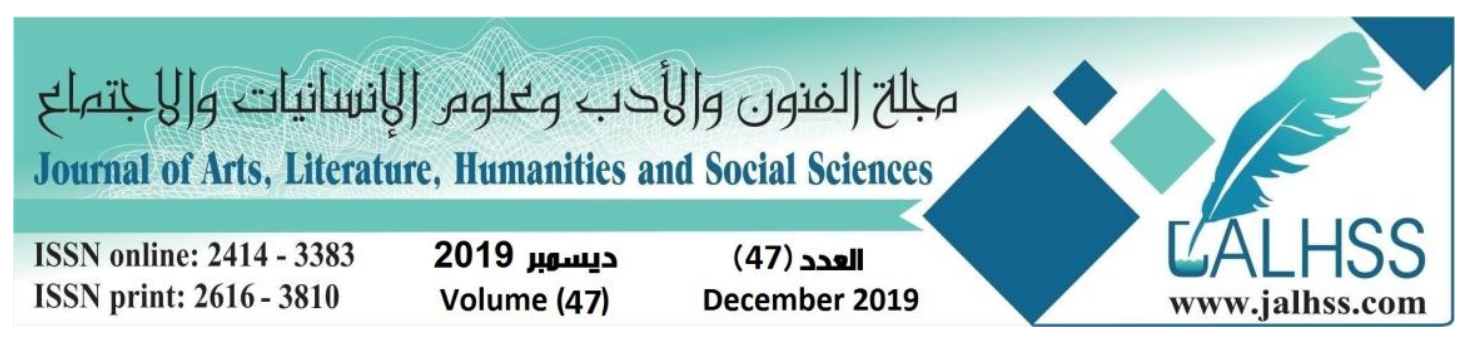

\section{References}

1. Sami Abdel Hamid, The Arabs in Shakespeare Theater, Comparative Study of Textual and Directional Approaches, Unpublished Doctoral Thesis, College of Fine Arts, University of Baghdad, 2004.

2. Ahmed Etman, Kilo Batra between History and Drama, Translated and Investigated by Mohsen Youssef, Presented by Ismail Serageldin, Bibliotheca Alexandrina, Cairo, 2009.

3. Albert Hourani, Islam in European Thought, Al-Ahlia for Publishing and Distribution, Beirut, 1994.

4. Boutarchos, The Greats: The Greats of the Greco-Romans and the Balance Between Them, Volume 1, Translated into Arabic by Michael Bishara Dawood, Dar Al Asr, Cairo, 1928.

5. Jerry Proton, Renaissance, translation. Ibrahim al-Bailey Mahrous, a review. Heba Naguib Maghrabi, Hindawi for Education and Culture, Cairo, 2014.

6. Abbas Mahmoud Al-Akkad, Shakespeare profile, Hindawi Foundation for Education and Culture, Cairo, 2013.

7. Abdul-Qahar Dawood Abdullah Al-Ani, Orientalism and Islamic Studies, Dar AlFurqan for Publishing and Distribution, Amman, 2000.

8. Adnan Mohammed Abdul Aziz Wazzan, The Image of Islam in English Literature, Ishbilia Publishing and Distribution House, Riyadh, 1998.

9. Mohsen Jassim Al-Musawi, Falling into the Circle of Magic Thousand and One Nights in English Literary Criticism 1704-1910, Al-Rasheed Publishing House, Baghdad, 1982.

10. Mahmoud Hamdy Zakzouk, Islam in the Perceptions of the West, Wahba Library, Cairo, 1987.

11. Mustafa al-Sibai, Sunnah and its position in Islamic legislation, Dar al-Warraq for publication and distribution - Islamic Bureau, d., 2000.

12. Shakespeare's Plays, King Henry IV, Vol. 1 and Vol. 2, 2nd Edition, Translated by Mustafa Taha Habib, Rev. Mohamed Shafik Ghorbal and Mohamed Badran, Dar El Maaref, Cairo, 1993.

13. Plays by Shakespeare, Richard III, Translation. Abdul Qader Al-Qat, Dar Al-Maaref, Cairo.

14. Plays Shakespeare, Henry V, Translation. Mohamed Awad Mohamed, review. Mohamed Shafik Ghorbal and Mohamed Badran, Dar El Maaref, Cairo, 1993.

15. William Shakespeare, Antony and Kilo Batra, translated by Louis Awad, Dar alKatib al-Arabi for Printing and Publishing, Cairo, 1968.

16. William Shakespeare, Othello, Arabization of Khalil Bishop, Dar Maroun Abboud, Beirut, 1974

17. William Shakespeare, Macbeth, translated by Hassan Ahmed Amin, Dar El Shorouk, Cairo.

18. William Shakespeare, Henry VI, Arabization of Antoine Rizkallah Mashati, supervised by Nazeer Abboud, Dar Nazeer Abboud.

19. William Shakespeare, Venice Merchant, translated by Hassan Ahmed Amin, Classical Library, Dar El Shorouk, Cairo, 1994.

A. C. Bradley, Shakespearean Tragedy, The Noonday. 


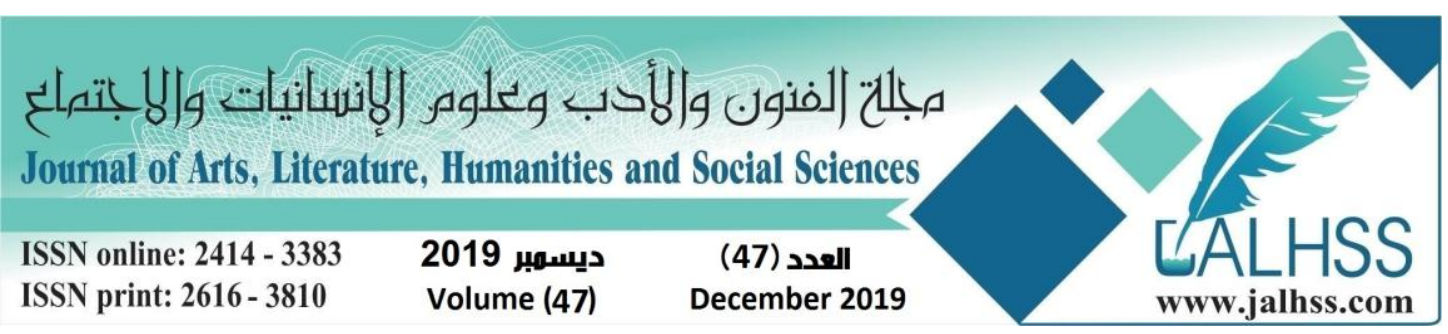

20. Jose Manuel Gonzalez, Shakespeare's Use of History in Escalas Criticism, Universitat d'alacant, 1998.

21. Richard F. Burton, The book of the Thousand nights and A night, Vol. 10, Oxford, 1885.

22. Sidney Lee, A Life of William Shakespeare, Ed. 4, Smith Elder \& CO 15 Waterloo, London, 1989.

23. Stratford-on-Avon District Local Plan Review 1996-2011, Revised Deposit Draft, January. 2003.

24. APA Style, Henry IV, Encyclopedia Britannica Ultimate Reference Suite. Chicago: Encyclopedia Britannica, 2010.

25. C.L. Kingsford, Henry V: The Typical Mediaeval Hero, Encyclopedia Britannica Ultimate Reference Suite. Chicago: Encyclopedia Britannica, 2010.

26. MLA Style, "Henry VI.", Encyclopedia Britannica Ultimate Reference Suite. Chicago: Encyclopedia Britannica, 2010.

27. MLA Style: "Stratford-on-Avon.", Encyclopedia Britannica, 2010.

28. The standard biography of the king is Charles Ross, Richard III, Encyclopedia Britannica, 2010.

29. Ibrahim Groom, Antonio and Kilo Batra: Love Defeats War, Life (Journal), 2014. WWW. Al-Hayat. Com

30. Alaa Hashim, Venice merchant. Shakespeare: The Dramatic Drama, The Way (Magazine), Number 29, Beirut, December, 2004

31. Mohammed bin Saad al-Shuwayer, reading in criticism of Shakespeare plays, an article. http://www.al-sunna.net.

32. Nader Zahir, Analysis and Criticism of Shakespeare's Othello, Donia El Watan (Magazine), Cairo, August. 2012.

33. A study in the analysis and criticism (play Othello) Shakespeare, Sunrise (magazine), Cairo, August, 2012. 